\title{
Probabilistic physical modelling of corroded cast iron pipes for lifetime prediction
}

\author{
Jian Ji \\ Department of Civil Engineering, Monash University, Vic 3800, Australia \\ Dilan Robert, \\ School of Civil, Environmental \& Chemical Engineering, RMIT University, Vic 3000, \\ Australia \\ Chunshun Zhang \\ Department of Civil Engineering, Monash University, Vic 3800, Australia \\ David Zhang \\ Sydney Water, 210 William Holmes St Potts Hill, NSW 2143, Australia \\ Jayantha Kodikara* \\ Department of Civil Engineering, Monash University, Vic 3800, Australia
}

*To whom correspondence should be addressed.

E-mail: jayantha.kodikara@monash.edu

\begin{abstract}
:
Cast iron was the dominant material for buried pipes for water networks prior to the 1970s in Australia and overseas. At present, many water utilities still have a significant amount of ageing cast iron pipes. Cast iron is a brittle material and when large diameter cast iron pipes (diameters above $300 \mathrm{~mm}$ ) further deteriorate, the consequences of failure can be substantial. Focusing on the likelihood of failure to assist risk assessment, this paper examines the performance of large-diameter cast iron pipes using probabilistic analysis, incorporating uncertainties of governing variables. Finite element analysis is first conducted to study the physical mechanism of buried pipes subjected to complex environmental conditions. The deterioration of cast iron pipes due to corrosion is considered on the basis of recent research. The uncertainties of governing variables, such as the physical properties of soil, cast iron, water pressure and corrosion patterns, in pipe failure risk assessment are considered. Using probabilistic physical modelling, the lifetime probability of failure is derived and a time-dependent sensitivity analysis is presented. The results of this probabilistic physical modelling are compared with cohorts of failure data from two Australian water utilities to examine the underlying trends from both physical modelling and statistical analysis.
\end{abstract}

Keywords: Pipeline failure; Stress prediction; Corrosion; Physical modelling; Probabilistic analysis 


\section{List of Notation}

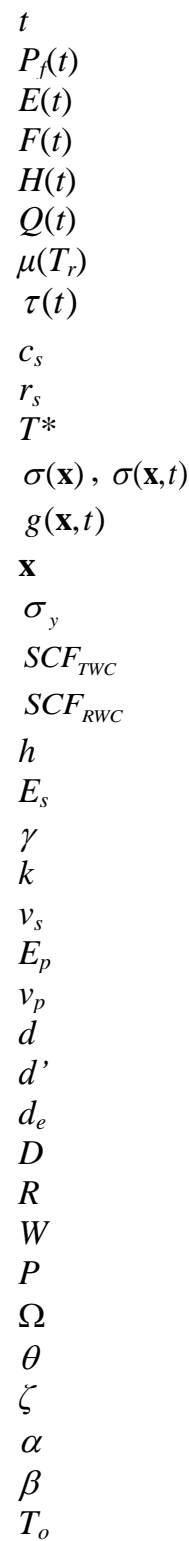

pipe lifetime or pipe age, year

probability of pipe failure at age $t$

expected lifetime or lifetime expectation

cumulative distribution function of random variable (lifetime) $t$

hazard rate

failure rate, in terms of number of failures $/ 100 \mathrm{~km} / \mathrm{year}$

mean residual lifetime when the pipe survival age is $T_{r}$, year

corroded depth when pipe is $t$ years old, mm

intercept of initial corrosion rate, $\mathrm{mm}$

long-term corrosion rate, $\mathrm{mm} / \mathrm{year}$

transition point of a bilinear corrosion model, year

time-independent and -dependent maximum tensile stress in pipe, MPa

limit state function defining the pipe failure and/or safety

a vector containing all physical parameters

tensile failure stress of pipe materials, MPa

stress concentration factor of through wall corrosion hole

stress concentration factor of remaining wall corrosion pit/patch

burial depth, $m$

elastic modulus of soils, MPa

unit weight, $\mathrm{kN} / \mathrm{m}^{3}$

lateral earth pressure coefficient

poisson's ratio of soils

elastic modulus of cast iron pipes, GPa

poisson's ratio of cast iron pipes

wall thickness, $\mathrm{mm}$

minimum remaining wall thickness in corrosion pit/patch, $\mathrm{mm}$

effective wall thickness of pipes subjected to uniform corrosion, $\mathrm{mm}$

nominal pipe diameter, $\mathrm{mm}$

nominal pipe radius, $\mathrm{mm}$

surface load (traffic), $\mathrm{kN}$

operating water pressure, $\mathrm{kPa}$

corrosion pit/patch radius, $\mathrm{mm}$

corrosion patch inclination, degree

ratio of uniform corrosion rate to pitting corrosion rate

shape parameter in Weibull distribution

scale parameter in Weibull distribution

location parameter in Weibull distribution, year 


\subsection{Introduction}

The management of water mains is an integral activity of water utilities in strategic planning, decision-making and asset management. Water mains can be broadly divided into small diameter (reticulation) (normally $<300 \mathrm{~mm}$ ) pipes or distribution mains of large diameter (normally $>300 \mathrm{~mm}$ ) pipes or trunk mains. Depending on the water network, a large majority of pipelines are small diameter pipes and the remainder are large diameter pipes. The large diameter pipes are normally given especial attention since their failures can incur significant consequences in the form of financial losses and societal or environmental impacts. Basically, all physical parameters are seen as various degrees of variation. As a result, in assessing pipe performance, there is less significance to define a lumped factor of safety, which essentially assumes that all physical parameters are well characterized by deterministic values. Instead, probabilistic analysis has proven to be a good alternative, and there has been an increasing demand for assessment of the lifetime probability of failure. This, in turn, can be used to evaluate the risk associated with failure [1]. In order to incorporate internal and external factors such as external loading changes, manufacturing material variations, internal water pressures, environmental effects, and variable deterioration due to pipe ageing, the probabilistic physical modelling approach is commonly utilized to analyse the lifetime probability of failure of pipelines. Typically, two types of probabilistic physical modelling approach are available: (1) numerical approximation based on engineering reliability methods; (2) Monte Carlo simulations. As an example of the first category, Ahammed and Melchers [2, 3] used the first-order second-moment (FOSM) reliability method to conduct probabilistic analyses of underground cast iron pipelines subjected to loadings and corrosion effects. With idealizations of the failure mechanism and timedependent corrosion behaviour, they demonstrated the computation of increasing failure probability or decreasing reliability index with time. DeSilva et al. [4] presented a probabilistic analysis to estimate the failure rates in metallic pipelines using FOSM. The condition assessment data were used to quantify the level of deterioration and to estimate the probability of failure of an entire pipeline over time. $\mathrm{Li}$ and Mahmoodian [5] demonstrated a methodology to quantitatively assess the lifetime risk of cast iron pipes and predict their remaining service life, based on the first passage probability theory. The concept of stress intensity in fracture mechanics is employed to establish the failure criterion of pipe collapse. An empirical model is derived for the maximum pit growth of corrosion from the available data based on mathematical regressions. As of the second category, Pandey [6] and Sinha and Pandey [7] presented a time to failure assessment of oil and gas pipelines using Monte-Carlo simulations (MCSs) that allow the incorporation of inspection and repair activities over their service life. Sadiq et al. [8] studied the performance of grey cast iron water mains by comparing the external stress with residual ultimate strength. A two-phase corrosion model was introduced to describe the wall thickness reduction in corrosion pits. MCSs were combined with their pipe failure models to derive the time to failure probability. Davis et al. [9] used MCSs to estimate lifetime probability distributions for PVC pipelines. Linear elastic fracture mechanics theory was used to predict the time to brittle fracture of pipes, and the uncertainty was taken into account for the failure process, and inherent defect size. The predicted failure rate was compared with the existing failure database recorded by water utilities. For metallic pipelines, the deterioration process is commonly approximated by corrosion that occurs at variable rates within the subsurface environment. Hence, it is imperative to 
base the estimation of corrosion progression on models that are validated by field evidence. A recent study comparing different corrosion models in pipeline reliability assessment is given in [10]. An extensive literature review of the probabilistic physical modelling technique is presented in [11], and [12]. In contrast to these probabilistic physical modelling studies, on the other hand, substantial research has been undertaken to introduce purely statistical approaches for pipeline failure prediction using the observed failure data [13-17]. However, comparisons between probabilistic physical modelling and the observed failure data are less commonly reported.

The aim of this paper is to study the likelihood of failure of aged cast iron pipelines using probabilistic physical modelling techniques. Realizing the fact that cast iron pipes were vastly used in Australia spanning from the year 1880 to 1970, this study will classify the cast iron pipes into different cohorts, for example, the pit cast iron pipes (mainly laid before 1925) and/or spun cast iron pipes (mainly between 1929 to 1970). The concept of pipe cohorting is very important to properly predict the pipe lifetime failure because it helps to reduce the variation within each of the cohorts. Using a field-validated corrosion model, the effect of time-dependent corrosion behaviour on pipe failure is examined. The significance of the proposed research is in advancing the knowledge of deterioration science of materials (cast iron and general metals) and the failure theory of infrastructure (buried pipelines), incorporating metal corrosion, soil mechanics, structural failure mechanics, and time-dependent reliability methods. The basic failure mechanism is investigated using finite element analysis, which is then used to derive a closed-form solution to predict maximum pipe stresses. Subsequently, an efficient first-order reliability method (FORM) [18, 19] combined with the importance sampling Monte Carlo simulation technique [20] is used to estimate the probability of failure of the pipe. Finally, a comparison is provided between the results of the probabilistic physical modelling and comparable results derived from observed failure data from two Australian water utilities.

Note that the findings in terms of the lifetime failure probability is based on the early designed cast iron pipes in Australia. Thus any prediction such made will be only valid to similarly defined pipe cohorts, and not for the recently designed pipes having different material properties.

\subsection{Deterioration of pipe structural capacity due to corrosion}

As cast iron pipelines were laid half a century ago, in most cases, their condition has deteriorated primarily by electro-chemical and (or) micro-biological corrosion. The corrosion activity (internal and external) can manifest in various forms, but generally leads to a reduction in pipe thickness, thereby causing deterioration of the pipe's structural capacity with respect to external and internal loads. On the basis of field evidence [21], the corrosion induced thickness loss is idealized into two patterns: uniform corrosion and pitting corrosion. Uniform corrosion applies when there is an all-round reduction in pipe wall thickness and pitting corrosion applies when there is a localised corrosion patch or pits. The latter can occur with or without the former. These idealized configurations are illustrated in Figure 1. 


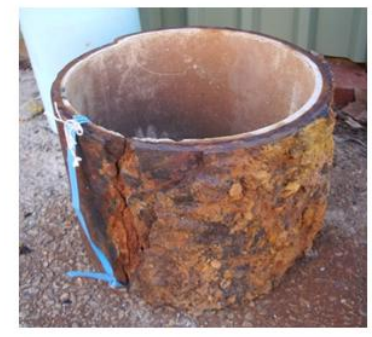

Field observation

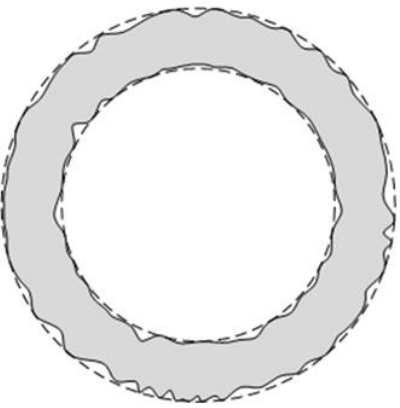

Idealisation of uniform corrosion pattern

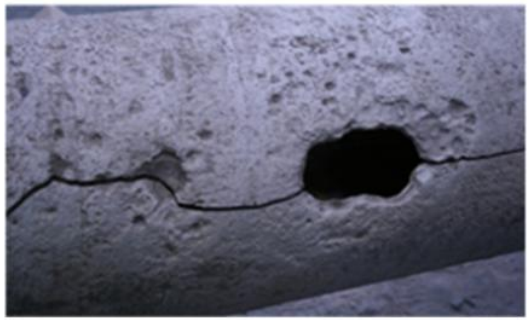

Field observation

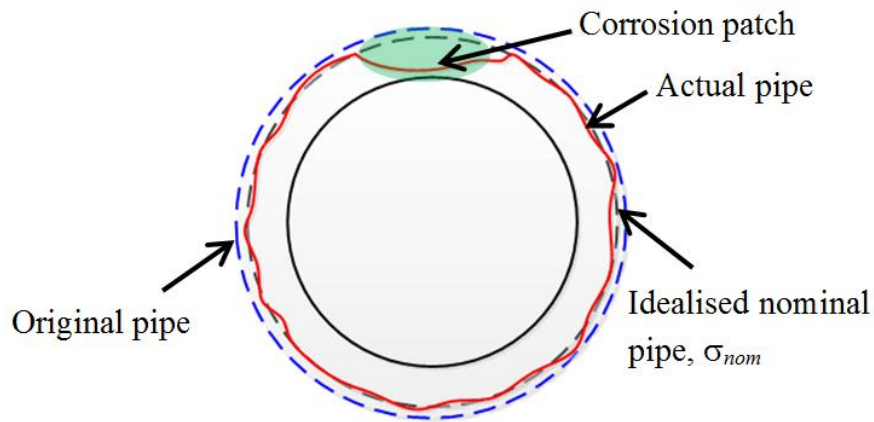

Idealisation of pitting corrosion pattern

Figure 1. Typical corrosion patterns observed in water mains failure

The corrosion of buried pipelines is a time-dependent process involving a number of complex processes $[22,23]$. In the literature, there are many studies which attempt to identify corrosion behaviour, and it has been well recognized that the rate of corrosion is not constant, but changes with time while featuring an initially high value $[10,14$, $24,25]$. For simplicity, these corrosion models all involve some unknown parameters that need to be evaluated by site observation data and/or experience. In this study, a field-validated model developed by the University of Newcastle, Australia through the 'Advanced Condition Assessment \& Pipeline Failure Prediction (ACAPFP) Project' is chosen for the analysis [26-28]. Focusing on the long-term corrosion behaviour, this model can be given as

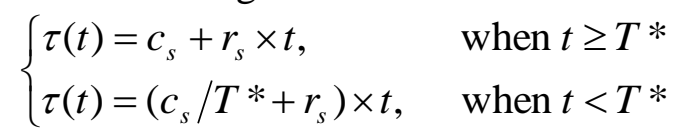

where $\tau(t)$ is the corroded depth when the pipe age is $t$ years, $T^{*}$ is the transit point of time from where the corrosion rate approaches a steady state value in equilibrium with the surrounding environment after an initially high rate. This is primarily an essential simplification of a multi-phase model for practical purposes. As many old buried pipelines are now in the steady state phase, $c_{s}$ and $r_{s}$ are particularly important, which characterise respectively the interception and corrosion rate of that phase, as illustrated in Figure 2. Eq. (1) provides a simplified but practically meaningful bilinear mathematical expression to capture the full development of corrosion over time; corrosion starts at a relatively quicker rate of $c_{s} / T^{*}+r_{s}$ till $t=T^{*}$, after which the corrosion rate decreases to a smaller rate of $r_{s}$. 


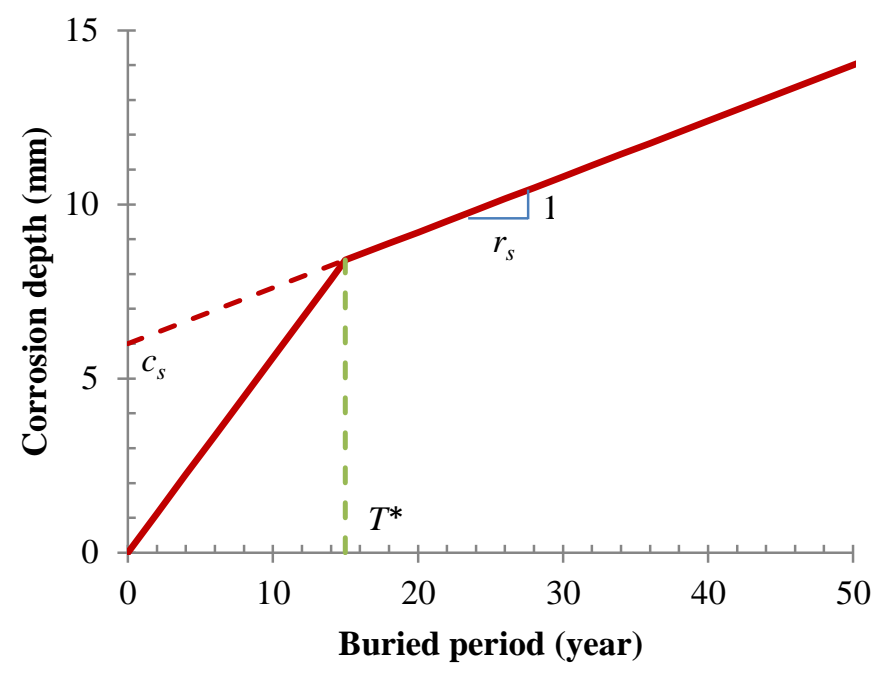

Figure 2. Schematic illustration of bilinear corrosion model [27]

3.0 Stress prediction of corroded cast iron pipes subjected to internal and external loading

In the management of large diameter water mains, pipe burst is a common issue that demands extensive studies due to the devastation it can cause. For cast iron pipelines, it is known that when working stress reaches the ultimate tensile strength, pipe burst becomes imminent, which can cause significant financial and social impacts to water utilities and communities. In this regard, it is necessary to investigate as accurately as practical the possible development of the pipe stress under internal and external loading conditions.

The current practice of estimating pipe stress primarily for new pipe design purposes is to use analytical and semi-empirical solutions, such as those developed by Sprangler [29], and Watkins and Anderson [30]. However, these widely-used solutions involve various assumptions and limitations, such as the neglect of threedimensional effects and the use of Winkler springs to analyse pipe-soil interaction. While these models are appropriate for pipe design where a factor of safety is used to safeguard against uncertainties, a more advanced approach is to solve the problem using 3-D finite element analyses to determine the stress distribution for a pipe at hand with a specific set of external and/or internal factors. The main internal factor is primarily the operating water pressure, $P$, and the external factors include earth pressure exerted from the surrounding backfilling soils and surface traffic loads, $W$, since in many cases, these trunk mains are laid under roads. The pressure can also come from water pressure under normal operation and any transient pressures that can develop due to operational effects such as pump start-ups, valve operation or failure of a pipe at a nearby location. Other physical parameters that can affect the stress state of buried pipes include pipe physical properties (diameter, thickness and modulus), corrosion geometry, and backfill soil conditions (such as initial density and lateral 
earth pressure resistance). Figure 3 shows a typical water pipe buried in soils, subjected to internal and external loadings.

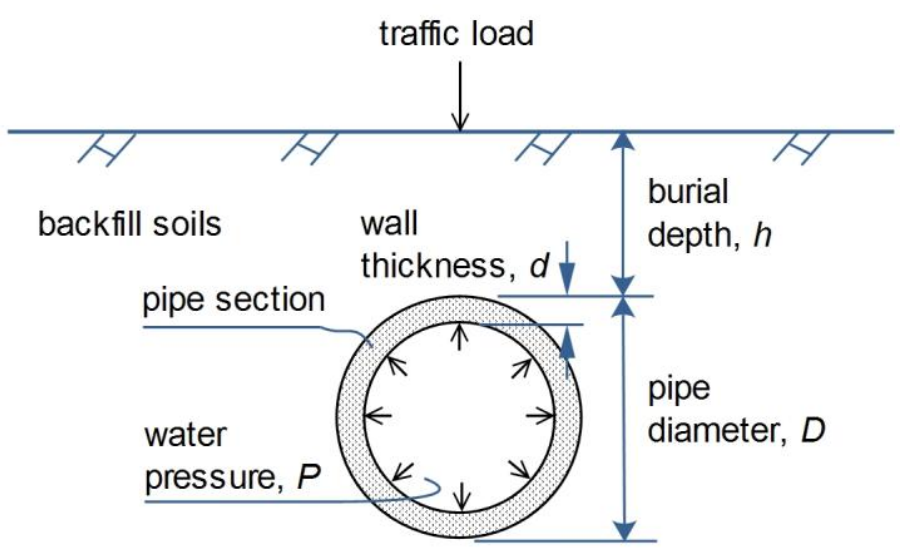

Figure 3. Simplified pipe burial conditions for water mains

\subsection{Prediction of working stress in pipes with general corrosion}

Based on Buckingham theorem, the working stress of pipes subjected to complex loading conditions can best be described using an expression involving a set of dimensionless variables as given in Eq. (1)

$$
\left(\frac{\sigma(\mathbf{x}) \cdot D^{2}}{W+\gamma \cdot D^{2} \cdot h}\right)=\phi\left(\frac{E_{p}}{E_{s}}, \frac{h}{D}, \frac{d}{D}, \frac{P}{E_{s}}, \frac{W}{\gamma D^{2} h}, k, v_{s}\right)
$$

where $\sigma(\mathbf{x})$ is the maximum stress in pipes, $\mathrm{x}$ is the vector of the dimensionless variables, and other symbols are as defined in Table 1 and Fig 3.

By learning from both Sprangler [29] and Schilck [31] equations, a closed-form expression of maximum stress in buried pipe was proposed as follows

$$
\frac{\sigma(\mathbf{x}) \cdot D^{2}}{W+\gamma \cdot D^{2} \cdot h}=\alpha_{1}\left(\frac{E_{p}}{E_{s}}\right)^{\beta_{1}}\left(\frac{E_{s}}{\gamma h}\right)^{\beta_{2}}\left(\alpha_{2} \frac{\left(\frac{P}{E_{s}}\right)^{\beta_{3}}}{\left(\frac{d}{D}\right)^{\beta_{4}}\left(\frac{W}{\gamma D^{2} h}+1\right)^{\beta_{5}}}+\alpha_{3} \frac{\left(\frac{d}{D}\right)^{\beta_{6}}\left(\frac{W}{\gamma D^{2} h}+1\right)^{\beta_{7}}}{\alpha_{4}\left(\frac{E_{p}}{E_{s}}\right)+\alpha_{5}\left(\frac{P}{E_{s}}\right)+\alpha_{6}\left(\frac{h}{D}\right)+\alpha_{7} k}\right)
$$

To determine the model constants, a series of variation of physical parameters based on available utility data as summarised in Table 1 are chosen and extensive FEM analyses using ABAQUS 6.11/standard were subsequently carried out. This results in a total of 6000 FEM simulation scenarios, based on which nonlinear regression analysis was conducted. As a result, the best-fitted model constants were given in Table 2, and the overall performance of the model was shown in Figure 4. Obviously, the model has been able to predict maximum stress of buried pipes with very high 
accuracy (i.e., $R^{2}=0.99$ ). Note that due consideration is given to large-diameter cast iron pipes mainly used in Australia. Further details of the regression model are available in [32] and [33].

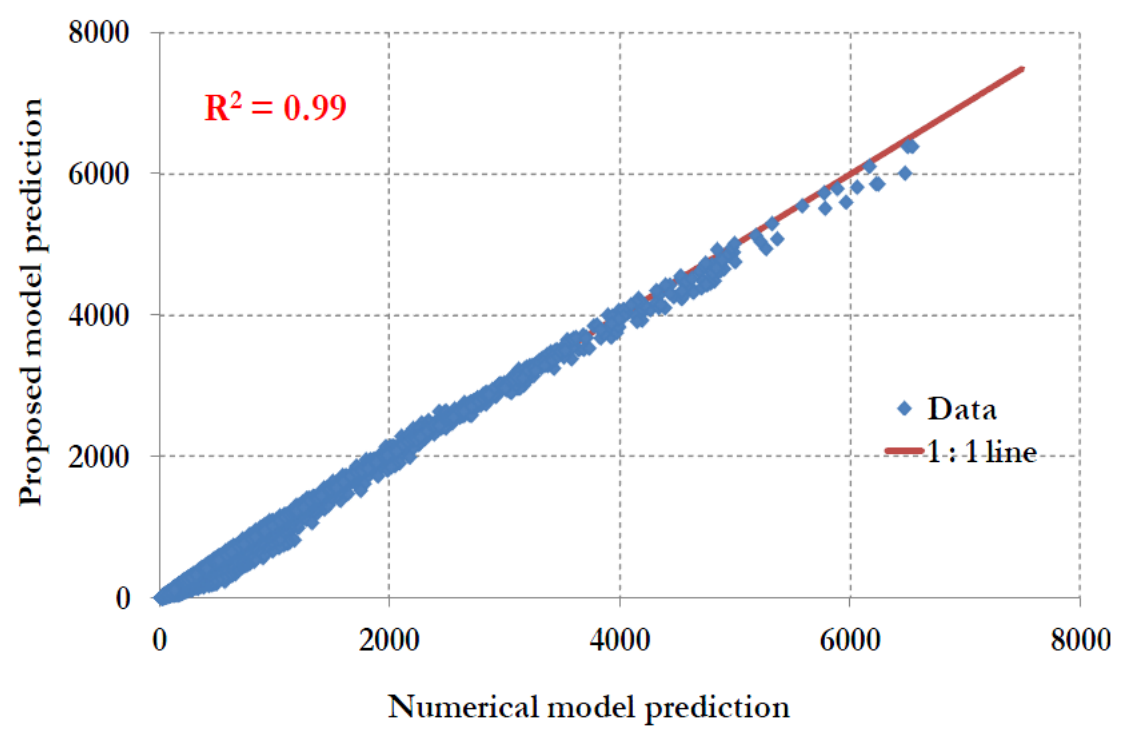

Figure 4. Performance of the nonlinear regression model for pipe stress prediction

Corrosion causes the gradual reduction of wall thickness. For pitting corrosion, the critical corrosion depth can be approximated by Eq. (1). The remaining wall thickness of a corrosion pit, $d$ ', is defined as

$$
d^{\prime}=d-\tau(t)
$$

On the other hand, in the case of concurrent occurrence of uniform corrosion, it is appropriate to couple the two corrosion patterns in the pipe stress analysis. An effective wall thickness $d_{\mathrm{e}}$ is introduced to describe the uniform corrosion deterioration, such that

$$
d_{e}=d-\zeta \tau(t)
$$

where $\zeta$ is a factor reflecting the uniform corrosion rate as a ratio to pitting corrosion rate.

$\zeta$ varies between 0 to 1 . Empirical values is usually used in the absence of observed data, but if no appreciable uniform corrosion is considered, then $\xi=0$ is used. In this paper, a preliminary investigation on the sensitivity of $\zeta$ to the pipe failure will be presented in the subsequent study. Generally, substituting $d_{\mathrm{e}}$ in place of $d$ in Eq. (2), one simply obtains the time-dependent nominal (working) stress $\sigma_{\text {nom }}(\mathbf{x}, t)$ for uniform corrosion. Obviously, the nominal stress increases with pipe ageing as a result of wall thickness reduction. Failure of pipes defined thus occurs when $\sigma(\mathbf{x}, t)>\sigma_{y}$, where $\sigma_{y}$ is the tensile strength of material. 


\subsection{Stress prediction of pipes subjected to corroded pits/patches}

Pitting and/or patch corrosion are common corrosion types, as observed from field inspections [34]. In addition to the uniform corrosion deterioration to cast iron pipes, the presence of such localised defects can significantly increase the principal stresses in the event of high internal and external loadings. The increase in stresses can be related with a stress concentration factor $(\mathrm{SCF})$, which is defined as the ratio of concentrated stress of the corrosion pit to the uniformly corroded (nominal) pipe stress. It is considered that a stress concentration factor is more relevant than a stress intensity factor, since these corrosion patches are generally spread out sub-rounded features. As the corrosion process is time-dependent, the working stress at time $t$ subjected to pitting/patch corrosion can be defined as

$$
\sigma(\mathbf{x}, t)=\sigma_{\text {nom }} \times S C F(t)
$$

Substantial analytical work has been conducted on the stress analysis of cylindrical sections with a circular hole for obtaining stress concentration effects [35, 36]. Most of this analytical work has been based on shallow thin shell theory and/or plane strain analysis, without considering any soil embedment effect. Figure 5 shows the stress concentration factors suggested by [35] for cylindrical shells with internal water pressure (considering membrane and bending effects). The results obtained from 3-D FE analyses are also shown in comparison with different pipe sizes and corrosion geometries. It can be seen that the analytical solutions generally agree with 3-D FE analysis predictions only for slightly corroded pipes [low values of $\left.\beta=\frac{\sqrt[4]{3\left(1-v^{2}\right)}}{2}\left(\frac{\Omega}{\sqrt{R d}}\right)\right]$ which are not embedded in soil. Considerable deviations are encountered once the pipe is subjected to larger patches of corrosion (i.e. higher $\beta$ ) as well as embedded effects in soil. It is also noted that the typical patch sizes of water mains are outside the validity region of shallow thin shell theory (Figure 6). 


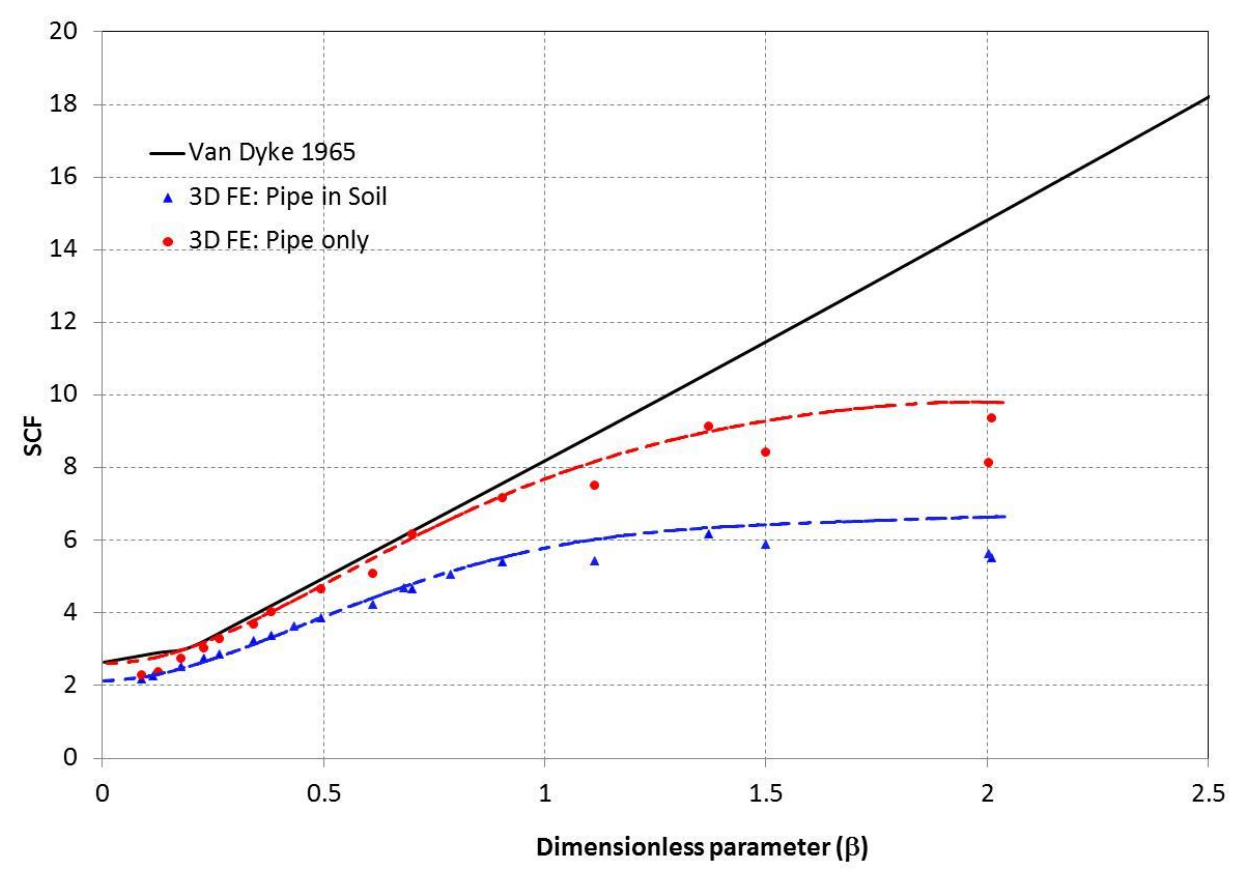

Figure 5. Comparison of SCF between 3-D FE analyses and Van Dyke (1965)

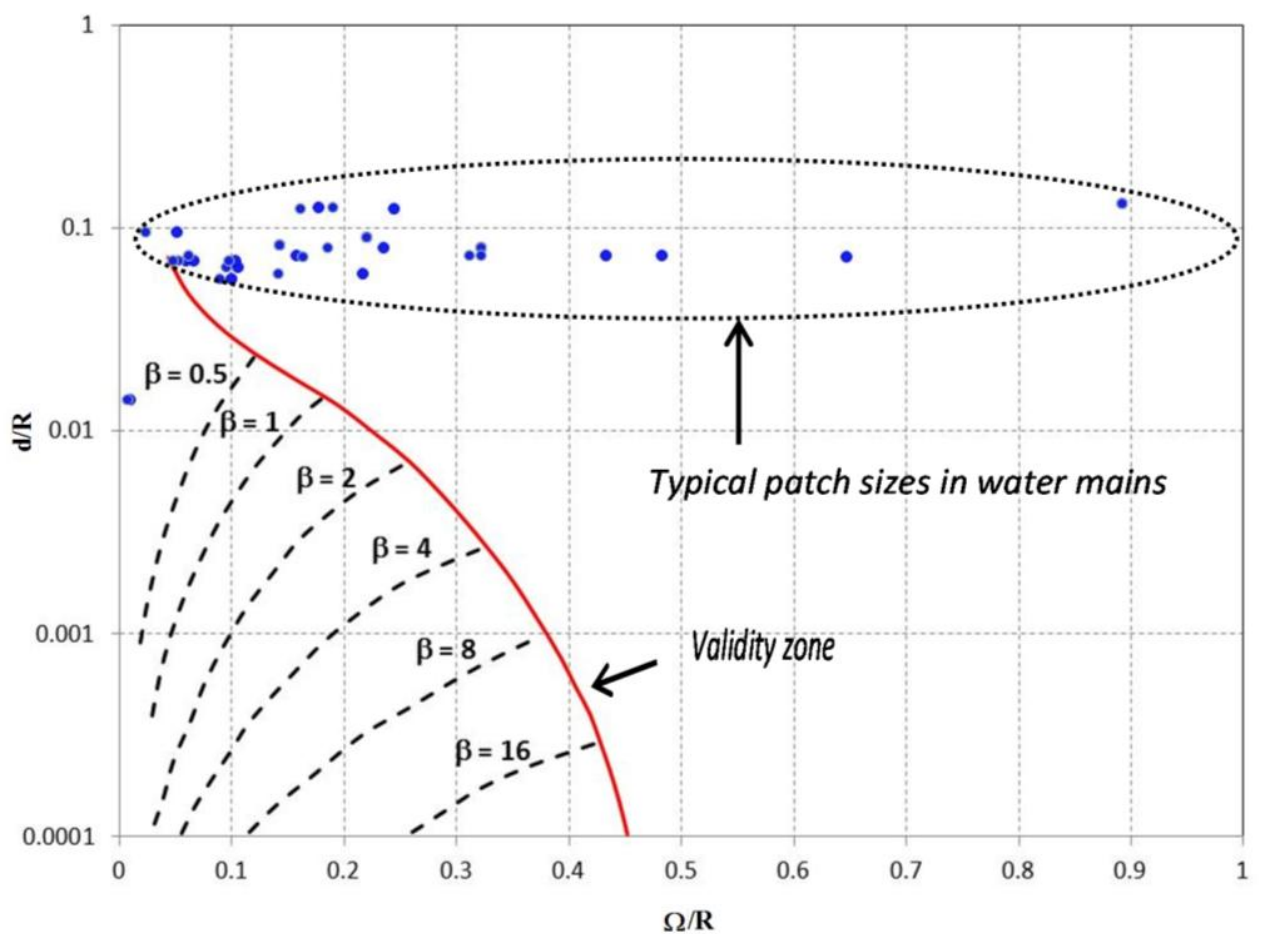

Figure 6. Region of validity of shallow, thin shell theory (modified from Van Dyke, 1965)

Due to the limitations encountered in the analytical solutions, a series of 3-D FE analyses was conducted to obtain more realistic SCFs for corroded pipes. Studies were undertaken to investigate the SCF of through-wall corroded pipes (Figure 7a) as well as remaining wall-corroded pipes (Figure 7b). Table 3 summarises the geometric 
parameters for pipe diameter, pipe thickness and corrosion geometry considered in the analysis.

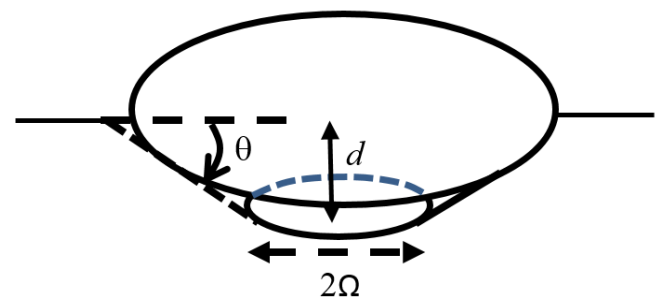

(a) Through-wall corrosion patch patch

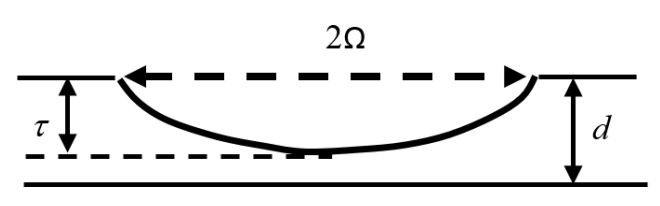

(b) Remaining wall corrosion

Figure 7. Schematic of the corrosion geometries for different patch corrosion types

Three-dimensional (3-D) finite element analyses were carried out using ABAQUS to obtain the stress state of the corroded pipes and to derive the non-linear regression models for predicting the stress concentration factors. The soil and pipe were represented by 8-noded brick reduced integration elements. The behaviour of both soil and pipe were assumed as a linear elastic material. Since cast iron can feature significant nonlinearity, plasticity models were also used, but it was found that linear models can provide reasonably accurate results for the maximum stress but not for the failure strain. Hence, for reasons of practicality of running a large number of models, linear elastic approximation was used for stress prediction. In addition, it was shown through non-linear analysis carried out by the authors (using the ABAQUS cast iron plasticity model) that generally up to working water pressures $(1000 \mathrm{kPa})$, the effect of cast iron non-linearity may not have significant influence. Furthermore, in any event, the linear elastic assumption would provide a somewhat conservative estimate of the maximum stress if the initial modulus is used. If a secant modulus (e.g., 50\%) is used, this error would diminish. The soil side boundaries of the FE model were assumed to be smooth and located far (i.e., 5m) from the pipe to eliminate any boundary effects. Based on the results obtained from the analyses, SCFs were obtained for pipes with different sizes and corrosion geometries.

Non-linear regression analyses were conducted to obtain regression models to fit the SCF derived from FE analysis. Eqs. (5) and (6) present the proposed regression models in computation of SCFs of through-wall $\left(S C F_{T W C}\right)$ corrosion and partial (remaining wall) corrosion $\left(S C F_{R W C}\right)$ pipes, respectively. The comparison of the SCFs obtained from regression models and FE analysis showed an acceptable goodness-of-fit, as shown in Figs. 8 and 9 for through-wall and remaining wall corrosion configurations, as given below: 
$S C F_{T W C}=5.4998 \times\left\{\frac{\sqrt[4]{3\left(1-v_{p}^{2}\right)}}{2} \cdot\left(\frac{\Omega}{\sqrt{R d}}\right)^{1.2} \cdot\left(\frac{1}{\sin \theta}\right)^{1.5}\right\}^{0.3377}$

$S C F_{R W C}=\frac{\left\{1.0-\alpha_{1}\left[1.0-\left(d^{\prime} / d^{\alpha_{2}}\right] \cdot M\left(\Omega, d, R, d^{\prime}, v\right)\right\}\right.}{\left\{1.0-\alpha_{1}\left[1.0-\left(d^{\prime} / d\right)^{\alpha_{2}}\right]\right\}}$

where, $M=\frac{\left(\alpha_{3} \times\left[\frac{\sqrt[4]{3\left(1-v_{p}^{2}\right)}}{2} \cdot\left(\frac{\Omega}{\sqrt{R d}}\right)\right]^{\alpha 4} \cdot\left(\frac{d^{\prime}}{d}\right)^{\alpha 5}+\alpha_{6} \times\left(\frac{\Omega}{R}\right)^{\alpha 7}\right)}{\left(\alpha_{8}\left(\frac{\Omega}{d^{\prime}}\right)^{\alpha 9}+\left(\frac{d^{\prime}}{d}\right)^{\alpha 10}\right)}$, symbols as defined previously in Tables 1 and 3 .

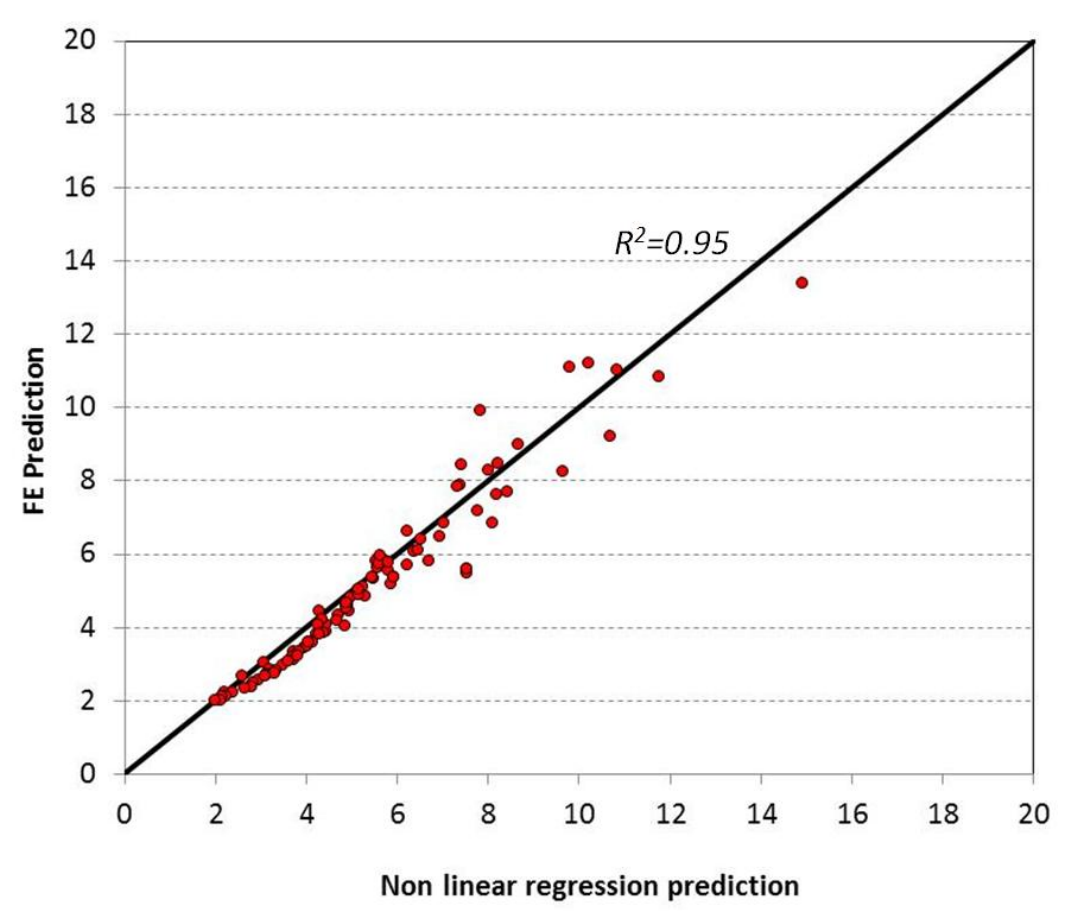

Figure 8. Comparison of SCF between the proposed non-linear regression model and FE analysis results for through-wall corrosion analysis 


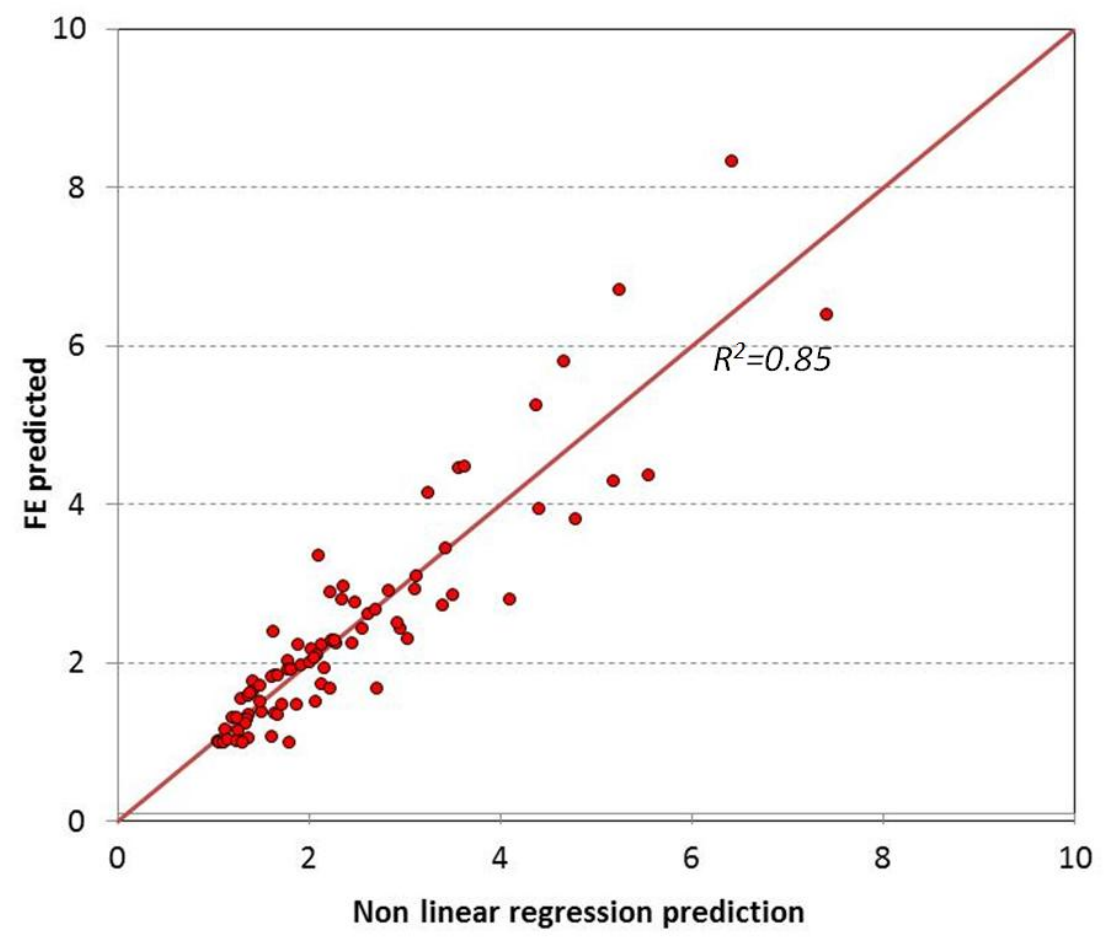

Figure 9. Comparison of SCF between the proposed non-linear regression model and $\mathrm{FE}$ analysis results for remaining wall corrosion analysis

4.0 Probabilistic physical modelling of corroded water mains

\subsection{Statistical analysis of physical parameters involved in pipe failure}

Prior to probabilistic physical modelling of pipelines, statistical information of the basic physical parameters is identified by analysing the failure data provided by some Australia water utilities. Basically, all physical parameters are seen as various degrees of variation. However, as far as the water utilities are concerned, only a few of these physical parameters are given priority for record-keeping. For instance, the operating pressure, wall thickness and diameter, as well as the age of pipelines are usually retained. The data records for many other parameters, such as the surrounding soils and surface load, may not be available. For this reason, this study aims to quantify the uncertainty of the physical parameters, the data records for which are available, and make reasonable assumptions for the other parameters. Beyond this study, further efforts will be directed to further scrutinize the variability of the parameters that are identified as most significant. For convenience, only the mean value and coefficient of variation $(\mathrm{COV})$ that are involved in probabilistic physical analysis are given here. The results are summarised in Table 5. 
It is widely recognized that the probabilistic method is a more advanced approach to investigate the failure probability for large diameter pipes, where failures are relatively infrequent, but can carry serious consequences due to failure. In the probabilistic analysis of deteriorated pipes, a time-dependent limit state surface (LSS) is first defined:

$$
g(\mathbf{x}, t)=\sigma_{y}-\kappa \sigma(\mathbf{x}, t)
$$

where $\mathbf{x}$ is the vector containing all physical parameters, $\sigma(\mathbf{x}, t)$ is time-dependent working stress as defined by Eqns. (2) to (4), and $\sigma_{y}$ is the tensile failure stress, in addition, $\kappa$ is a coefficient to account for the model uncertainty that comes from the imperfectness of the working stress models given by Eqns. (2) to (4). For pristine cast iron material, $\sigma_{y}$ has been taken as a time-invariant property for cast iron pipelines. This assumption is reasonable, since much of the strength variation with age comes from the corrosion or graphitisation of the metal [37], and we have taken the corrosion explicitly in our calculations. For a given set of these parameters at a specific time, the pipe is safe when $g(\mathbf{x}, t)>0$, fails when $g(\mathbf{x}, t)<0$, and at the limit state when $g(\mathbf{x}, t)=0$.

From a probabilistic point of view, the LSS involves a joint probability density function which is difficult to attain analytically. As a result, the probability of failure $P_{f}\{g(\mathbf{x}, t)<0\}$ is usually assessed approximately. The approximation can be done by MC simulation or an numerical approach such as FORM [38, 39]. Each of the two methods has advantages and disadvantages. For example, the former is the standard way of probability inference but would be computationally intensive for tail probability problems (which is the case of this study); the latter can provide more insights into pipe physical reliability but may not be accurate in the computation of probability of failure. For computational efficiency, a hybrid reliability analysis is carried out to derive the pipe failure probability by: (1) using an optimization-based FORM realized in MS-EXCEL spreadsheet $[18,19]$ to locate the design point; and (2) assessing the failure probability around this design point by importance sampling MC simulations with significantly less computational effort [20].

\subsection{Probabilistic physical modelling of corroded pipelines: results and discussion}

Based on the above-mentioned LSS which couples uniform corrosion with pitting corrosion patterns, probabilistic assessments were subsequently performed on different pipe sections. Note that in order to concentrate our discussion on the physical parameters, the coupling factor $\zeta$ as shown in Eq. (3b) is empirically assumed to be $1 / 5$ for the next parametric studies. Additional sensitivity analysis of $\zeta$ will be discussed at the last. Focusing on critical pipes (large-diameter cast iron trunk water 
mains), the cohort is characterized by pipe diameter, and four typical values are chosen herein for extensive parametric studies. These include $300 \mathrm{~mm}, 400 \mathrm{~mm}, 500$ $\mathrm{mm}$ and $600 \mathrm{~mm}$ diameter cohorts. Corresponding to the specified cohort diameter, the wall thickness usually takes various values, but is generally positively correlated to diameter. For example, most cast iron pipes manufactured in Australia between 1930 's to 1980's have an increasing wall thickness with diameter, as shown in Figure 10. Obviously, this indicates almost linear relationships between the mean values of the two physical parameters. According to this information, the mean values of wall thickness are respectively 14.5, 17.0, 19.5, and $22.0 \mathrm{~mm}$. By discretising the life-time of pipes into a series of points, the life-time probability of failure is computed as shown in Figure 11(a). Interestingly, these life-time probabilities are regarded in timeto-failure reliability engineering as cumulative distribution functions (CDFs) with respect to failure age/time, $t$ [40]. For the convenience of mathematical expression, they can be represented by fitted curves of the type of Weibull distribution

$$
F(t: \alpha, \beta)=1-e^{\left.-\left\{\left(t-T_{0}\right) / \beta\right)\right\}^{\alpha}}
$$

where $T_{0}$ is the location parameter, $\alpha$ the shape parameter and $\beta$ the scale parameter. Based on these expressions, another useful information called hazard rate functions is readily inferred as

$$
H(t: \alpha, \beta)=\frac{d F(t: \alpha, \beta) / d t}{1-F(t: \alpha, \beta)}=\frac{\alpha}{\beta}\left(\frac{t-T_{0}}{\beta}\right)^{\alpha-1} e^{\left.-\left\{\left(t-T_{0}\right) / \beta\right)\right\}^{\alpha}}
$$

The best fitted Weibull curves as well as hazard rate functions are also shown in Figure 11(b), all with coefficients of determinant $R^{2}$ of more than 0.99. The Weibull parameters obtained for each pipe cohort are shown in Table 6.

In the lifetime reliability analysis, a useful information is the mean residual lifetime, MRL, which is the expected remaining servicing lifetime beyond the current (survival) age $T_{r}$. By definition, the MRL at age $T_{r}$ is

$$
\mu\left(T_{r}\right)=E\left\{t-T_{r} \mid t>T_{r}\right\}=\left[\int_{T_{r}}^{\infty}[1-F(x)] d x\right] /\left[1-F\left(T_{r}\right)\right]
$$

where $E(\cdot)$ and and $F(\cdot)$ denote the expectation and CDF, respectively.

Substituting Eq. (8) into Eq. (10), the MRL for three-parameter Weibull distribution is obtained as follows

$$
\mu\left(T_{r}: \alpha, \beta\right)=\left[\int_{T_{r}}^{\infty} e^{-\left(x-T_{0} / \beta\right)^{\alpha}} d x\right] / e^{-\left(T_{r}-T_{0} / \beta\right)^{\alpha}}, \quad \forall T_{r} \geq T_{0}
$$

In general, the integral in the above equation cannot be explicitly solved. On the other hand, numerical solutions for the Weibull-type MRL can be attained, and the results with respect to the four pipe cohorts are presented in Figure 12.

The physical modelling results show that the hazard rate is an increasing type through the lifetime of the pipes analysed. Another interesting observation from Figure 11 is that all of these cases experience negligible hazard at their early ages, e.g., before $T_{0}$. 
This period of time is usually referred to as the honeymoon-period (HMP) for buried pipes. The HMP has been well-known in the water utility community, but this calculation provides evidence from a physical mechanistic point of view. The HMP appears to increase as the pipe diameter and particularly, the wall thickness increases. In addition, it is noted that after the HMP, pipes undergo probability of failure increases at a high rate initially and then the rate tends to drop towards the pipe failure. The rates of probability of failure seem to be inversely associated with both the pipe diameter and wall thickness. In other words, the pipe failure risk can be delayed by using a larger diameter pipe that is usually built with bigger wall thickness. This again shows the significant role of pipe wall thickness in determining long-term pipe safety.

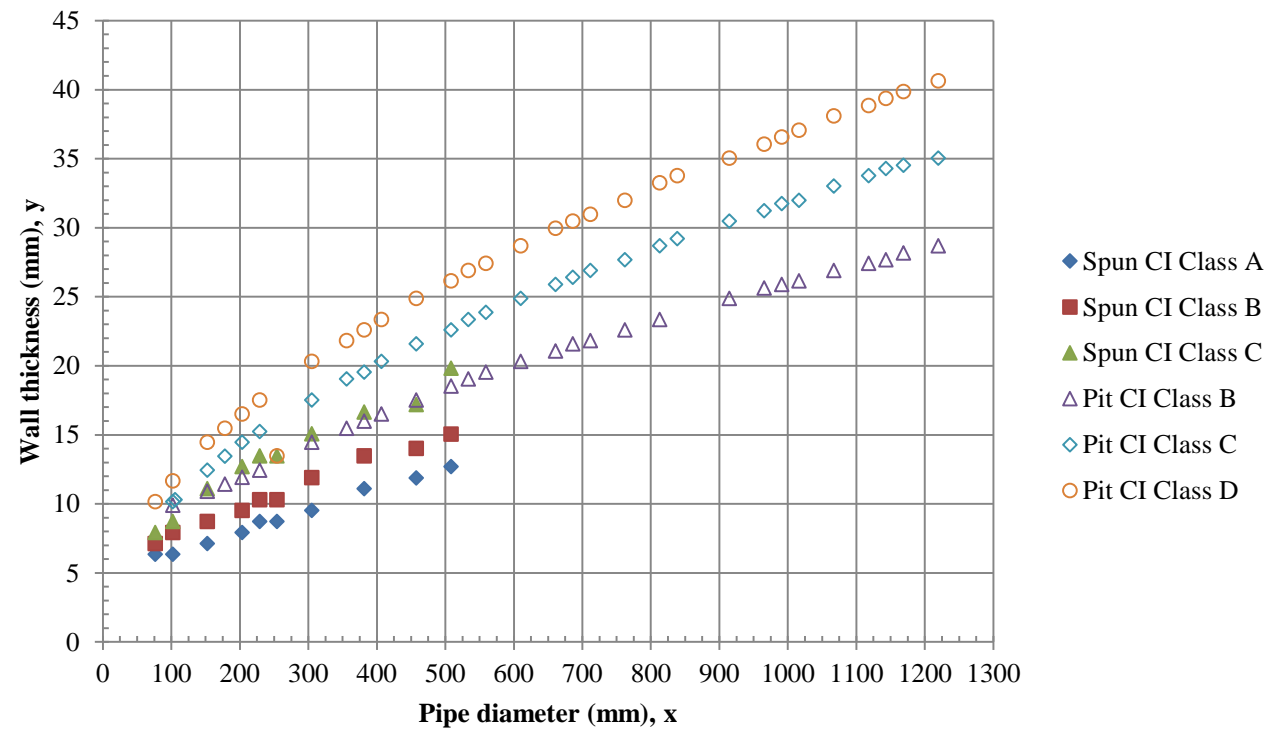

Figure 10. Relationship between wall thickness and pipe diameter for cast iron pipes (AIS, 1941)
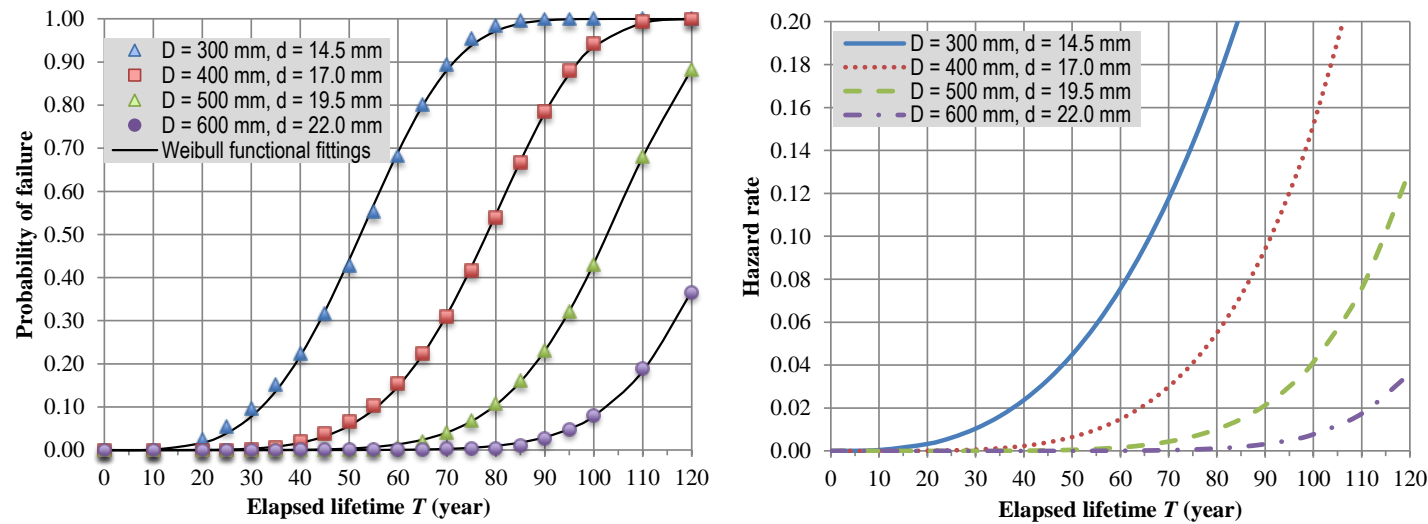

Figure 11. Life-time probability of failure for corroded pipelines 


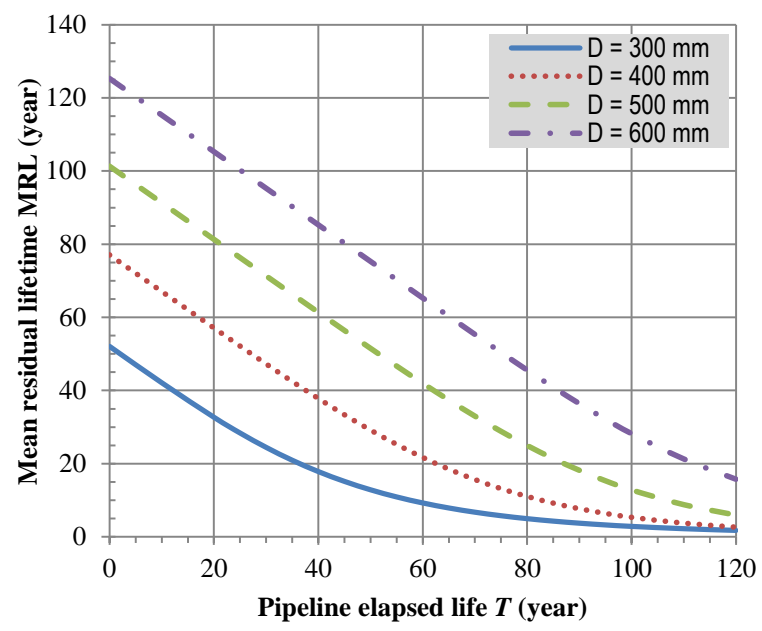

Figure 12. Prediction of the mean residual lifetime for corroded pipelines

Note that the above findings are based on the linear relationship between wall thickness and pipe diameter. On the other hand, the pipeline failure inspection records supplied by Australian water utilities show scattered pipe thickness values with diameter as shown in Figure 13, due to various construction practices. The influence of these likely variations is also examined in the probabilistic study as follows. To begin with, the statistical correlation coefficient (which defines how closely two sets of data in a scatterplot fall along a straight line) between wall thickness and pipe diameter is first determined from the inspected samples. For example, this value is about 0.66 for Sydney Water mains, and 0.68 for Hunter Water mains. It is anticipated that the correlation coefficient would vary with the data provided. Nevertheless, this coefficient is of secondary consideration in our probabilistic analysis and therefore, a nominal value of 0.7 is reasonably assumed for the subsequent probabilistic study. In addition, a constant mean value of $15 \mathrm{~mm}$ and coefficient of variation of 0.3 are derived for wall thickness. In actual application of this technique, it is possible to consider cohorts of pipes of similar characteristics to refine the analysis. Based on these assumptions, the life-time failure probabilities with respect to different pipe diameters are presented in Figure 14, together with Weibull curve fittings by Eq. (8) and hazard rate functions by Eq. (9). The obtained Weibull parameters for each cohort are listed in Table 7. The Figure 14 shows almost opposite phenomena in comparison with Figure 11, in that the larger diameter pipe tends to have higher risk, although the difference is not very significant among different pipe diameters. This finding demonstrates that the wall thickness has a larger impact on the lifetime failure probability of pipelines than does the pipe diameter. 

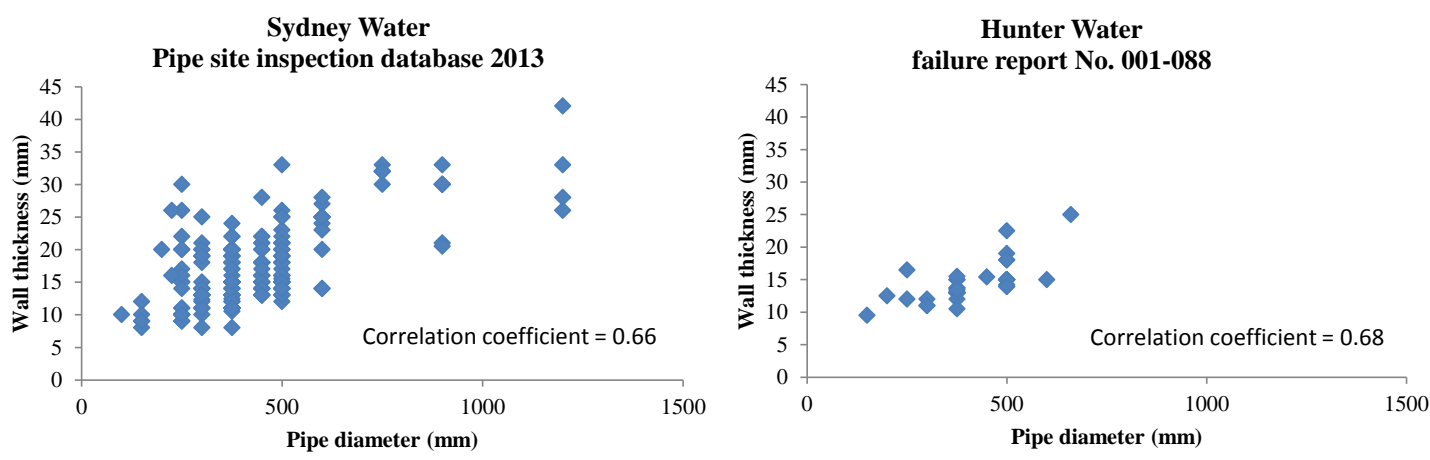

Figure 13. Correlation analysis of wall thickness and pipe diameter from utilities' data records
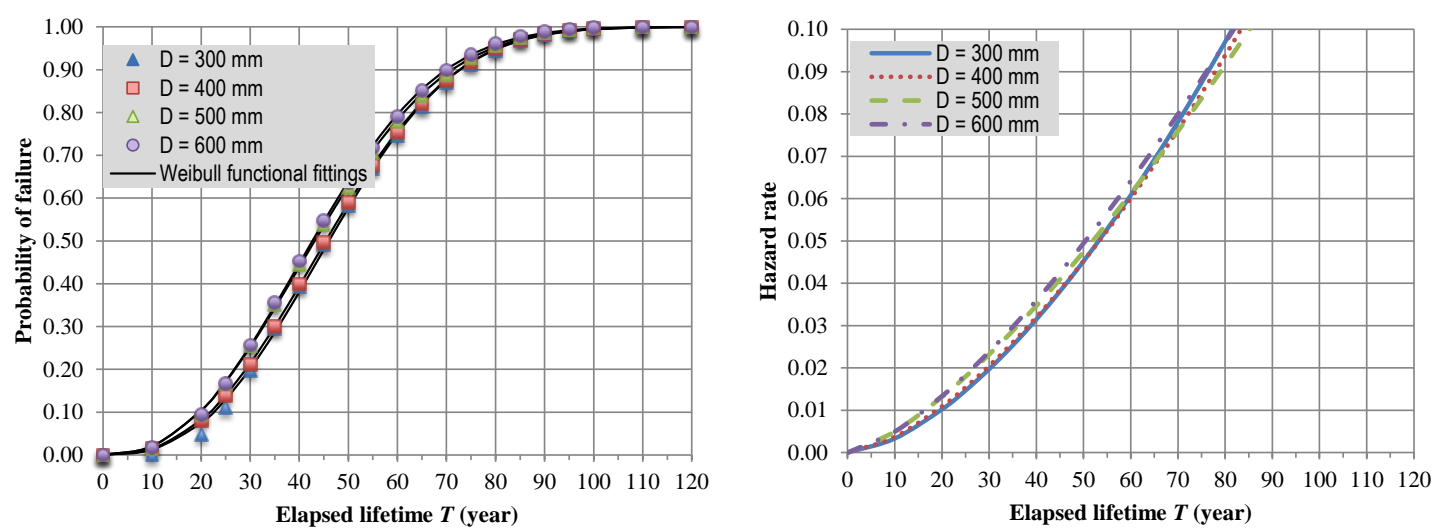

Figure 14. Life-time probability of failure for corroded pipelines with equal mean value of wall thickness

In addition to the empirically selected corrosion coupling factor $\zeta$, Figure 15 illustrates the influence of $\zeta$ on the consequent probability of failure of the pipe. Four scenarios of collocation of uniform and pitting/patching corrosion are selected for sensitivity analysis. The $\zeta$ valued at $1 / 2$ can be regarded as significant uniform corrosion, whilst 1 /infinity represents no uniform corrosion. In general, the influence of uniform corrosion tends to decrease when $\zeta$ 's are at smaller values, e.g., less than 1/5. Another interesting observation is that when the pipe lifetime grows the effect of $\zeta$ may become noticeable, implying that the uniform corrosion would play more important roles in the late stage of lifetime. It is anticipated that in absence of reliable statistical data, such a preliminary sensitivity analysis of $\zeta$ may provide some useful insights into the study of coupling behaviour between uniform and pitting/patching corrosions on the buried pipes. 


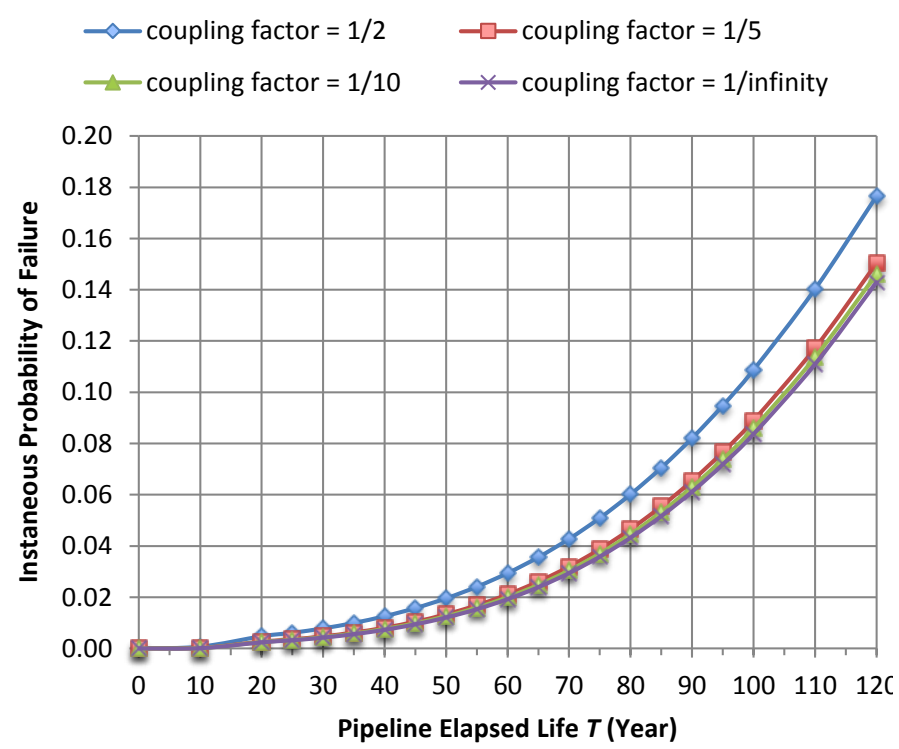

Figure 15. Sensitivity of the corrosion coupling factor to the predicted probability of pipe failure

Apart from the before-mentioned uncertainty analysis, there are many other sources of uncertainty influencing the failure probability in the probabilistic physical modelling of water mains. Some parameters may dominate pipe performance, while others are only covariates that have very minimal effects. In order to examine this, the probabilistic sensitivity index can be considered as useful information to demonstrate these effects. In particular, Figure 16 presents the results of probabilistic sensitivity analysis with respect to the $600 \mathrm{~mm}$ diameter pipe, based on the statistical information given in Table 5. As can be seen, the probabilistic sensitivity indices of different physical parameters change with pipe ageing. In other words, the probabilistic sensitivity is also time-dependent. Interestingly, they can be categorized into positive and negative factors, implying that the probability of pipe failure would increase with those physical parameters having positive sensitivity index, and vice versa. Some physical parameters, such as traffic magnitude, soil modulus, and pipe modulus, have negligible influence on the probability of failure, at all stages of pipe ageing. Among these physical parameters that have noticeable influence on the probability of failure, it seems that the influence of pipe geometric properties such as the wall thickness and pipe diameter to the failure probability remains significant over pipe ageing. Note that for a specific pipe, these geometric properties usually have lesser variation, hence their actual sensitivity contribution will be less than predicted herein. In contrast, the external environmental factors such as the operating water pressure and corrosion behaviour, seem to consistently increase their contribution to the probability of failure. Moreover, the significance of corrosion parameters $c_{\mathrm{s}}$ and $r_{\mathrm{s}}$ changes dynamically; initially $c_{\mathrm{s}}$ is more important than $r_{\mathrm{s}}$, but the latter overwhelms the former gradually. This implies that for aged pipes the probability of pipe failure comes mainly from the corrosion behaviour, especially the long-term corrosion rate $r_{\mathrm{s}}$. This is because by this time, the corrosion patches have progressed significantly and there is only a small remaining wall thickness. As shown in Figure 17, at this time, the stress increases 
almost exponentially, as the remaining wall thickness at the base of the patch further increases. Hence, the corrosion rate which governs this reduction dominates the time to failure.
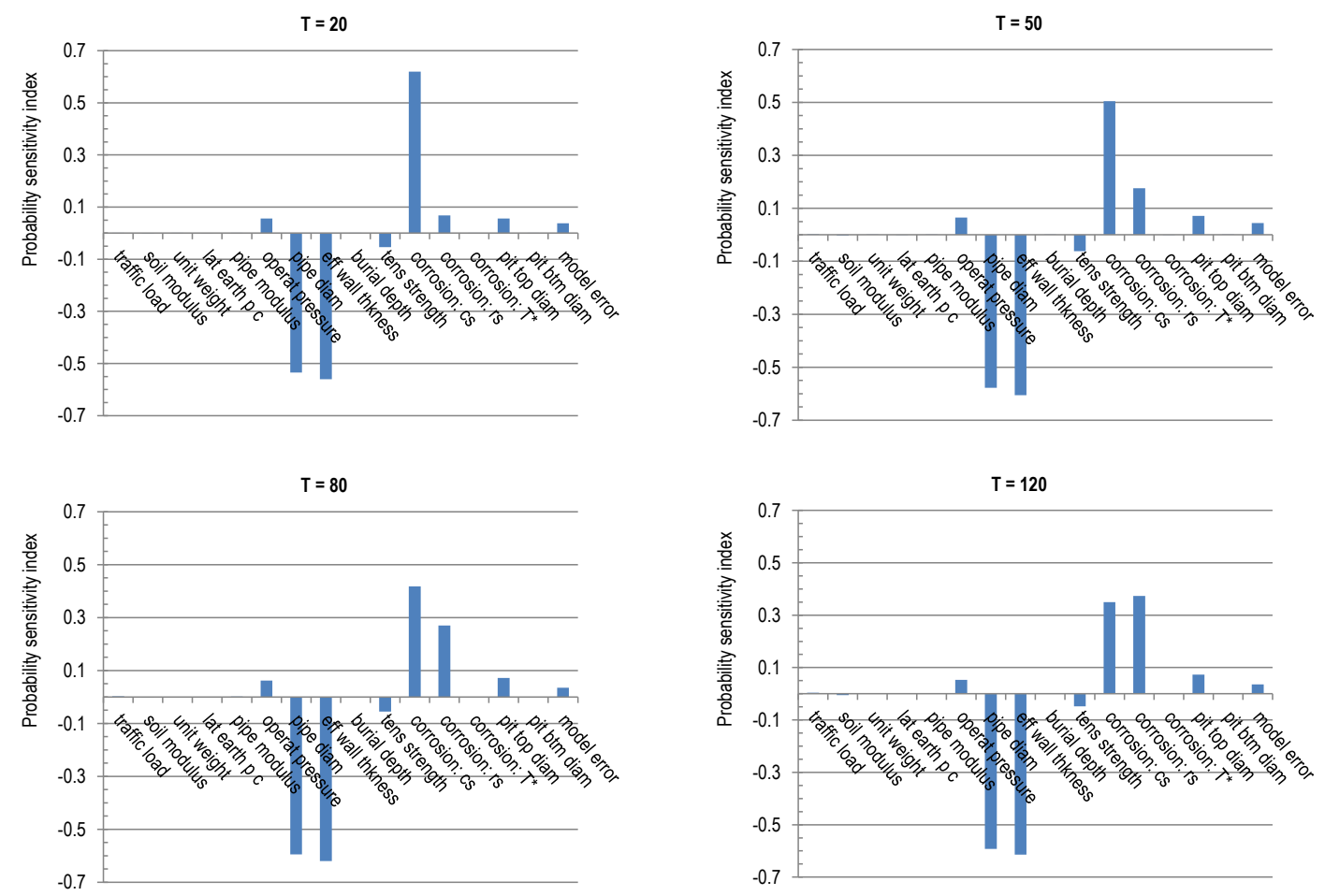

Figure 16. Change of probability sensitivity index with pipe ageing

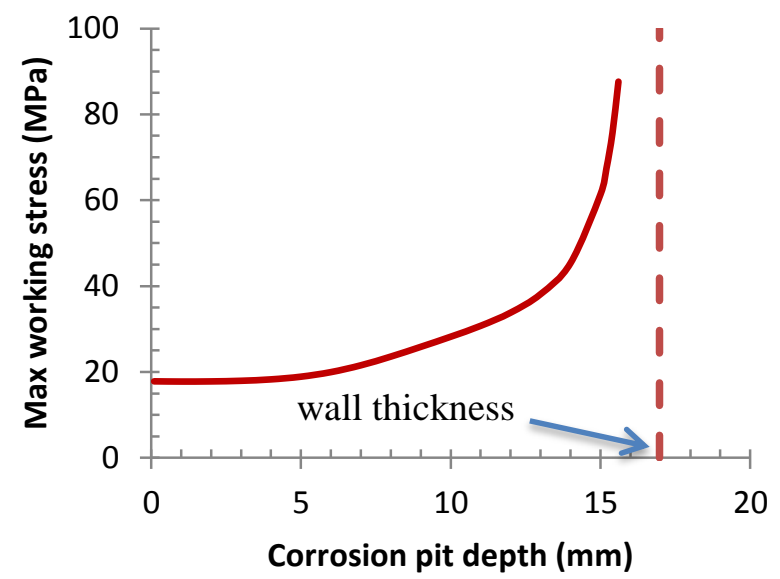

Figure 17. Change of working stress due to corrosion

5.0 Comparison between physical modelling and observed pipeline failures

As illustrated through the previous sections, it seems that the probabilistic physical modelling technique can reasonably explain the pipe lifetime failure probability. This is usually referred to as the bottom-up method, where pipe-soil interaction mechanism incorporating the statistical characterisation of input variables is the basis of the modelling technique. On the other hand, some studies have tried to interpret the 
pipeline lifetime failure probability by purely looking at the statistics of observed failure data (outcomes), producing the so-called top-down method. Both methods have their advantages and disadvantages, but there seems to be a gap between them, as seen from the literature $[11,12,41]$. In our viewpoint, it is reasonable to compare the results from the two different perspectives and if possible, to further update some information on these physical parameters. This prompts the following comparative studies between top-down and bottom-up analyses.

For the top-down analysis, it is essential to gather sufficient pipeline failure observations from historical record. For this purpose, we examined two sets of Australia critical pipeline (cast iron) failure records provided by Hunter Water and Sydney Water, respectively. According to Hunter Water, there were 831 cast iron cement-lined (CICL) water main failures due to various reasons, as recorded from 1998 to 2012. Similarly, there were 1556 CICL water main failures recorded by Sydney Water from 2000 to 2012. These broken pipes were installed in the last century ranging from 1900 to 1978. For each failure data set, sorting by the pipe failure age, the probability mass function, PMF, against time is first explored. For the convenience of mathematical comparison, the obtained PMF is transformed to the hazard rate, which is well-known in studying time-to-failure systems. By doing so, the results from top-down analysis are easily obtained and shown in Figure 18(a) for Hunter Water and Figure 18(b) for Sydney Water.

For the bottom-up analysis, preliminary statistical examinations were carried out to the pipe diameters which have been well recorded by the utilities. A mean value of $418 \mathrm{~mm}$ and COV of 0.25 for pipe diameter were derived from Hunter Water failure data, and a mean value of $410 \mathrm{~mm}$ and COV of 0.4 derived from Sydney Water failure data. In addition, they all fall into the range between 300 and $600 \mathrm{~mm}$, which are typical to the large diameter pipes. In view of the actual boundary values indicated by the data record, Beta distributions were fitted to the pipe diameters with results of shape parameters such that: $\mathrm{B}(1.8,3)$ for Hunter Water and $\mathrm{B}(1,2.5)$ for Sydney Water. The pipe wall thickness is calculated according to the mean of pipe diameter according to manufacturing standard, with a wall thickness COV of 0.10 to consider the potential manufacturing tolerance. Meanwhile, we have made some assumptions and carried out preliminary statistical characterizations of the key physical parameters. For example, we employed nominal soil parameters as presented in Table 5 to study the two sets of the pipeline failure records. Another underlying assumption in conducting probabilistic physical modelling for the failure data is that the two data sets are subjected to similar corrosion behaviour with the same corrosion model. The so-obtained results are also shown in Figure 18. It is obvious that the bottom-up analysis can produce similar lifetime risk prediction to the top-down analysis, with more or less discrepancy as a result of unknown factors. In fact, due to the incompleteness of data records before 1998 (for Hunter Water) and 2000 (for Sydney Water), there could be a lack of reliability in the PMF and/or hazard rate of the observed data. Furthermore, it is also possible to learn from the failure data to update 
some other physical properties dominating the pipe performance through probabilistic physical modelling, combined with systematic back-analysis tools utilising failure data (such as Bayesian methods or Markov-Chain-Monte-Carlo simulations). This is beyond the scope of this paper, and we are progressing on the development of more attractive methodologies in order to efficiently combine both bottom-up and top-down approaches realising the value of both physical reasoning and observed patterns of failure.

It is also worth pointing out that, since the current probabilistic physical modelling is limited to non-repairable systems, our top-down assessment also assumes a first-timeto-failure system (non-repairable) for the pipelines, but not a repairable system involving failure inspections and replacements $[15,40]$.

(a)

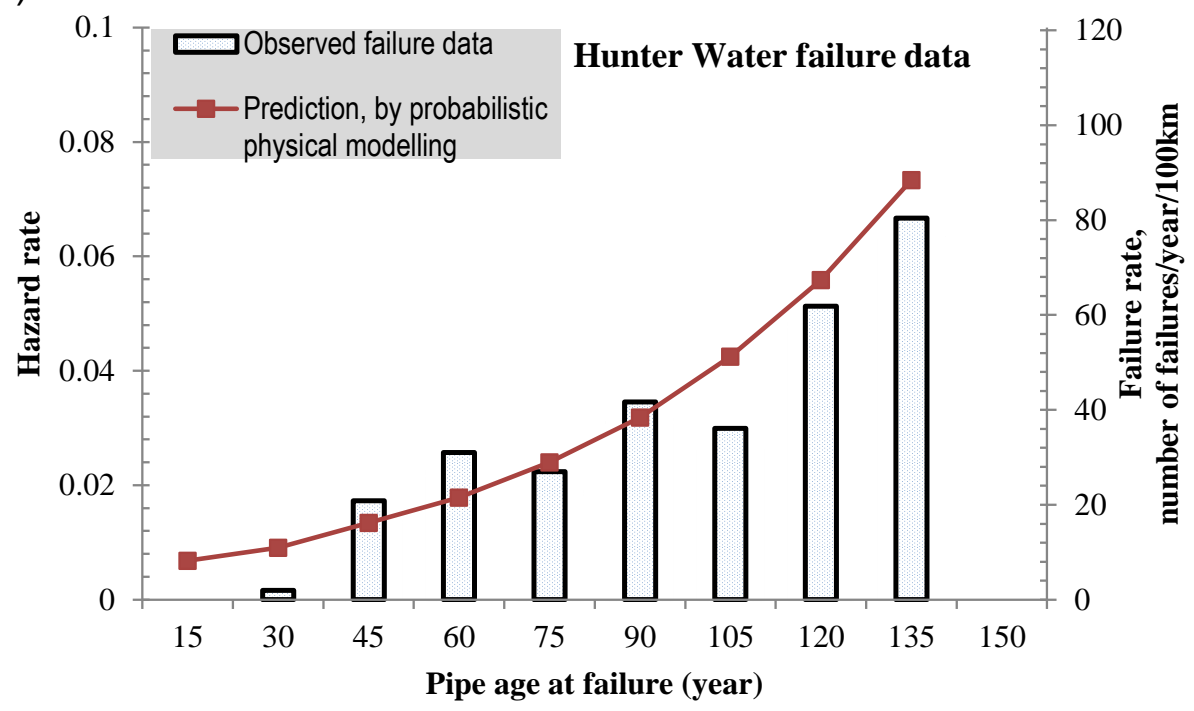


(b)

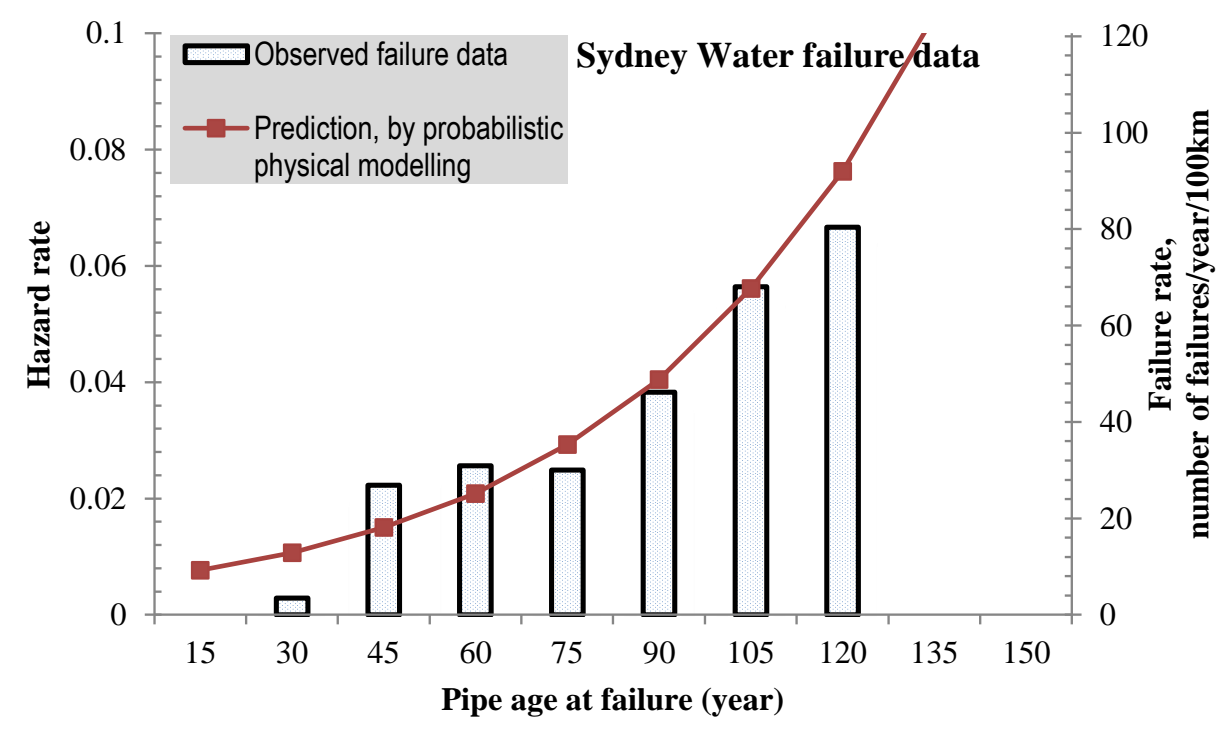

Figure 18. Comparison between probabilistic physical modelling (marked lines) and observed failure data (bars)

\subsection{Prediction of the failure rate of pipelines}

The failure rate, in terms of number of failures per $100 \mathrm{~km}$ per year, is commonly recognized by water utilities as a basis for failure prediction for their assets. The hazard rate as obtained from probabilistic physical modelling as well as the statistical failure data analysis can be easily converted into this practically useful failure rate. Assuming statistical independence between pipes' failure, the following relationship holds

$$
Q(t)=H(t) \times N_{t}
$$

where $\mathrm{Q}(t)$ denotes failure rate, in units of number of failures per $100 \mathrm{~km}$ per year, $\mathrm{H}(t)$ is the hazard rate for a typical pipe (section), and $N_{t}$ is the number of pipes (sections) for a $100 \mathrm{~km}$ cohort in a particular year $t$.

Hunter Water failure data contain a total of 832 failures of cast iron pipes, with lengths varying from several meters up to $500 \mathrm{~m}$, and some long pipes can experience multiple failures after repair. On average, each failure can happen on a typical length of $83 \mathrm{~m}$. As a result, it is deemed that a $100 \mathrm{~km}$ cohort will roughly consist of $N_{t}=$ 1205 such typically long pipes that are at risk of failure. This, in turn, is used to produce the predicted failure rate $\mathrm{Q}(t)$, as shown in Figure 18(a) by the second vertical axis. Similarly, the predicted failure rate $\mathrm{Q}(t)$ for Sydney Water is shown in Figure 18(b) by the second vertical axis.

\subsection{Conclusion}


In this paper, the lifetime probability of failure of Australian cast iron pipes used as trunk water mains was investigated using numerical simulations and probabilistic methods. On the basis of field evidence, corrosion modes were idealized and using finite element stress analysis and parametric studies, closed-form solutions to predict maximum pipe stress amenable to probabilistic analyses involving large numbers of simulations were established. These solutions incorporate most relevant parameters governing pipe-soil interaction process as applicable to a corroded cast iron pipe.

The study then discussed the importance of uncertainty of some physical properties of soil, cast iron, water pressure and corrosion pattern in the computation of the failure probability of water mains. From the sensitivity analysis, it was shown that the lifetime probability of failure is highly related to the pipe thickness and tensile strength, operating (water) pressure, and depth and breadth of corrosion geometry encountered. On the basis of the analysis undertaken, a 50- to 80-year time frame is more relevant to water utilities given their pipe cohorts. For pipes around 50 years of age, the sensitivity-based importance of parameters in descending order are the pipe diameter/wall thickness, corrosion rate, tensile strength, operating pressure, and how extensive is the corrosion patch (or patch diameter). If pipes survive to much higher ages like 120 years, the long-term corrosion rate would become an important factor dominating the probability of failure. Interestingly, soil parameters and traffic loads do not feature dominant sensitivity to the results.

Finally, comparison of the probabilistic physical modelling was made with statistical results of water mains failure data provided by two Australian water utilities. It was shown that the two methods (i.e., top-down and bottom-up approaches) can play complementary roles in studying the risk of buried pipelines and failure prediction, and this is considered in future research work. This can lead to the realization of the value of both approaches to produce more credible outcomes for the industry in the sphere of large-diameter trunk mains management. It should also be noted, that while interesting insights were gained through this study, more work is necessary to examine other issues. For example, other corrosion patch configurations such as noncircular patches and clusters of patches or pits need to be considered to cater for condition assessment interpretations. Actual applications must be made only after closer examination of the pipe cohorts and the associated data.

Because the proposed model is specifically developed for cast iron pipes in Australia, the results may be more useful for predicting the risk of Australia CI pipelines. However, the methodology as explained in this paper is generic. To extend the proposed modelling technique to current pipelines or those of other regions, one needs to use their own inputs to run the probabilistic model.

\section{Acknowledgments}

This publication is an outcome of the "Advanced Condition Assessment \& Pipeline Failure Prediction Project (ACA\&PFPP)" funded by Sydney Water Corporation, Water Research Foundation of the USA, Melbourne Water, Water Corporation (WA), UK Water Industry Research Ltd, South Australia Water Corporation, South East Water, Hunter Water Corporation, City West Water, Monash University, the 
University of Technology Sydney and the University of Newcastle. The research partners are Monash University (lead), the University of Technology Sydney, and the University of Newcastle. 


\section{References}

1. Jiang, S.-H., Li, D.-Q., Zhang, L.-M., Zhou, C.-B. Time-dependent system reliability of anchored rock slopes considering rock bolt corrosion effect. Engineering Geology 2014; 175(0): 1-8.

2. Ahammed, M., Melchers, R.E. Probabilistic analysis of underground pipelines subject to combined stresses and corrosion. Engineering Structures 1997; 19(12): 988-994.

3. Ahammed, M., Melchers, R.E. Probabilistic analysis of underground pipelines subject to pitting corrosion leaks. Engineering Structures 1995; 17(2): 74-80.

4. Silva, D.D., Moglia, M., Davis, P., Burn, L.S. Condition Assessment and Probabilistic Analysis to Estimate Failure Rates in Buried Pipelines. Journal of Water Supply: Research and Technology-Aqua 2006; 55(3): 179-191.

5. Li, C.Q., Mahmoodian, M. Risk based service life prediction of underground cast iron pipes subjected to corrosion. Reliability Engineering \& System Safety 2013; 119(0): 102-108.

6. Pandey, M.D. Probabilistic models for condition assessment of oil and gas pipelines. NDT \& E International 1998; 31(5): 349-358.

7. Sinha, S.K., Pandey, M.D. Probabilistic Neural Network for Reliability Assessment of Oil and Gas Pipelines. Computer-Aided Civil and Infrastructure Engineering 2002; 17(5): 320-329.

8. Sadiq, R., Rajani, B., Kleiner, Y. Probabilistic risk analysis of corrosion associated failures in cast iron water mains. Reliability Engineering and System Safety 2004; 86(1): 1-10.

9. Davis, P., Burn, S., Moglia, M., Gould, S. A physical probabilistic model to predict failure rates in buried PVC pipelines. Reliability Engineering \& System Safety 2007; 92(9): 1258-1266.

10. Valor, A., Caleyo, F., Hallen, J.M., Velazquez, J.C. Reliability assessment of buried pipelines based on different corrosion rate models. Corrosion Science 2013; 66: 7887.

11. Rajani, B., Kleiner, Y. Comprehensive review of structural deterioration of water mains: physically based models. Urban Water 2001; 3(3): 151-164.

12. St. Clair, A.M., Sinha, S. State-of-the-technology review on water pipe condition, deterioration and failure rate prediction models! Urban Water Journal 2012; 9(2): 85-112.

13. Duchesne, S., Beardsell, G., Villeneuve, J.-P., Toumbou, B., Bouchard, K. A Survival Analysis Model for Sewer Pipe Structural Deterioration. Computer-Aided Civil and Infrastructure Engineering 2013; 28(2): 146-160.

14. Sheikh, A.K., Boah, J.K., Hansen, D.A. Statistical Modeling of Pitting Corrosion and Pipeline Reliability. Corrosion 1990; 46(3): 190-197.

15. Qin, J., Faber, M.H. Risk Management of Large RC Structures within Spatial Information System. Computer-Aided Civil and Infrastructure Engineering 2012; 27(6): 385-405.

16. Watson, T.G., Christian, C.D., Mason, A.J., Smith, M.H., Meyer, R. Bayesian-based pipe failure model. Journal of Hydroinformatics 2004; 6: 259-264.

17. Mahmoodian, M., Alani, A. Modeling Deterioration in Concrete Pipes as a Stochastic Gamma Process for Time-Dependent Reliability Analysis. Journal of Pipeline Systems Engineering and Practice 2013; 5(1): 04013008. 
18. Low, B.K., Tang, W.H. Reliability analysis using object-oriented constrained optimization. Structural Safety 2004; 26: 69-89.

19. Low, B.K., Tang, W.H. Efficient spreadsheet algorithm for first-order reliability method. Journal of Engineering Mechanics 2007; 133(12): 1378-1387.

20. Melchers, R.E. Importance sampling in structural systems. Structural Safety 1989; 6(1): 3-10.

21. Rajeev, P., Kodikara, J., Robert, D., Zeman, P., Rajani, B. Factors contributing to large diameter water pipe failure, Water Asset Management Journal. Water Asset Management Journal 2014; 10(3): 9 - 14.

22. Cole, I., Marney, D. The science of pipe corrosion: A review of the literature on the corrosion of ferrous metals in soils. Corrosion science 2012; 56: 5-16.

23. Melchers, R.E. Long-term immersion corrosion of steels in seawaters with elevated nutrient concentration. Corrosion Science 2014; 81(0): 110-116.

24. Rajani, B., Makar, J. A methodology to estimate remaining service life of grey cast iron water mains. Canadian Journal of Civil Engineering 2000; 27(6): 1259-1272.

25. Caleyo, F., Velázquez, J.C., Valor, A., Hallen, J.M. Probability distribution of pitting corrosion depth and rate in underground pipelines: A Monte Carlo study. Corrosion Science 2009; 51(9): 1925-1934.

26. Petersen, R.B., Melchers, R.E., Long term corrosion of buried cast iron pipes in native soils, in (In) Corrosion and Prevention. 2014: Darwin, Australia.

27. Petersen, R.B., Melchers, R.E., Long-term corrosion of cast iron cement lined pipes, in (In) Corrosion and Prevention. 2012: Melbourne, Australia.

28. Petersen, R.B., Dafter, M., Melchers, R.E., Modelling the long-term corrosion of cast iron pipes, in (In) Corrosion and Prevention. 2013: Brisbane, Australia.

29. Spangler, M.G., The Structural Design of Flexible Pipe Culverts, in Bulletin 153, lowa Engineering Experiment Station. 1941: Ames, lowa.

30. Watkins, R.K., Anderson, L.R. Structural Mechanics of Buried pipes. New York: CRC Press. 2000.

31. Schlick, W., Supporting strength of cast iron pipe for gas and water services, in Bulletin 146, lowa Engineering Experimental Station, Ames, IA. 1940.

32. Robert, D., Rajeev, P., Kodikara, J., Rajani, B. An equation to predict maximum pipe stress incorporating internal and external loadings on buried pipes. Canadian Geotechnical Journal 2016; 53(8): 1315-1331.

33. Kodikara, J., Pipe stress prediction models for uniform pipes, in Fact Sheet No. 13 2014: http://www.criticalpipes.com/publications/fact-sheets/.

34. Rajeev, P., Kodikara, J., Robert, D., Zeman, P., Rajani, B., Factors Contributing to Large Diameter Water Pipe Failure as Evident From Failure Inspection. 2012: Australia.

35. Van Dyke, P. Stresses about a circular hole in a cylindrical shell. AIAA Journal 1965; 3(9): 1733-1742.

36. Lekkerkerker, J. Stress concentration around circular holes in cylindrical shells, Report presented at the Ilth Intern. Congr. of Applied Mechanics, Munich 1964.

37. Seica, M., Packer, J. Mechanical Properties and Strength of Aged Cast Iron Water Pipes. Journal of Materials in Civil Engineering 2004; 16(1): 69-77.

38. Haldar, A., Mahadevan, S. Probability, reliability and statistical methods in engineering design. New York: Wiley. 2000.

39. Melchers, R.E. Structural reliability analysis and prediction. New York: John Wiley \& Sons. 1999.

40. Ebeling, C.E. An introduction to reliability and maintainability engineering. 2 nd ed. Long Grove, Illinois: Waveland Pr Inc. 2004. 
41. Kleiner, Y., Rajani, B. Comprehensive review of structural deterioration of water mains: statistical models. Urban Water 2001; 3(3): 131-150. 
Table 1 Physical properties for large-diameter cast iron buried pipes

\begin{tabular}{|l|l|l|l|l|}
\hline Description of physical parameters & Symbol & Unit & Value for NLR \\
\hline Location & Burial depth & $h$ & $\mathrm{~m}$ & $0.3,0.8,1.3,2.0$ \\
\hline \multirow{2}{*}{$\begin{array}{l}\text { Backfill } \\
\text { soil } \\
\text { surrounding } \\
\text { pipelines }\end{array}$} & Elastic modulus & $E_{s}$ & $\mathrm{Mpa}$ & $2,4,10,25,50$ \\
\cline { 2 - 5 } & Unit weight & $\gamma$ & $\mathrm{kN} / \mathrm{m}^{3}$ & 18.5 \\
\cline { 2 - 5 } & $\begin{array}{l}\text { Lateral earth pressure } \\
\text { coefficient }\end{array}$ & $k$ & & $0.1,0.25,0.4$ \\
\cline { 2 - 5 } & Poisson's ratio & $v_{s}$ & & 0.3 \\
\hline \multirow{2}{*}{$\begin{array}{l}\text { Pipe } \\
\text { physical } \\
\text { properties } \\
\text { (cast iron) }\end{array}$} & Elastic modulus & $E_{p}$ & $\mathrm{Gpa}$ & 100 \\
\cline { 2 - 5 } & Poisson's ratio & $v_{p}$ & & 0.3 \\
\cline { 2 - 5 } & Wall thickness & $d$ & $\mathrm{~mm}$ & $4,8,10,15,27$ \\
\cline { 2 - 5 } & Pipe diameter & $D$ & $\mathrm{~mm}$ & $300,660,1000$ \\
\hline \multirow{4}{*}{ Load } & Surface load (traffic) & $W$ & $\mathrm{kN}$ & 0 to 75 \\
\cline { 2 - 5 } & $\begin{array}{l}\text { Operating water } \\
\text { pressure }\end{array}$ & $P$ & $\mathrm{kPa}$ & $\begin{array}{l}0,300,500,800,1000,1300, \\
1500\end{array}$ \\
\hline
\end{tabular}

Table 2 Constants of the proposed stress prediction model determined by nonlinear regression analysis

\begin{tabular}{|c|c|c|c|c|c|c|c|}
\hline Parameter & $\alpha_{1}$ & $\alpha_{2}$ & $\alpha_{3}$ & $\alpha_{4}$ & $\alpha_{5}$ & $\alpha_{6}$ & $\alpha_{7}$ \\
\hline Value & 0.12 & 4.08 & $-1.76 \mathrm{E}+06$ & $7.65 \mathrm{E}+04$ & $4.17 \mathrm{E}+06$ & $-3.23 \mathrm{E}+07$ & $-3.55 \mathrm{E}+07$ \\
\hline Parameter & $\beta_{1}$ & $\beta_{2}$ & $\beta_{3}$ & $\beta_{4}$ & $\beta_{5}$ & $\beta_{6}$ & $\beta_{7}$ \\
\hline Value & 0.086 & 0.94 & 0.89 & 0.88 & 0.94 & -0.51 & -0.71 \\
\hline
\end{tabular}

*The coefficients were estimated using the results from the numerical analyses performed for the range of parameters in Table 1. 
Table 3 Variability of geometric properties selected in the FE analysis

\begin{tabular}{|l|c|c|c|}
\hline $\begin{array}{l}\text { Physical } \\
\text { Parameter }\end{array}$ & Unit & $\begin{array}{c}\text { Variations for } \\
\text { corroded remaining } \\
\text { wall analysis }\end{array}$ & $\begin{array}{c}\text { Variations for } \\
\text { corroded through } \\
\text { wall analysis }\end{array}$ \\
\hline Pipe diameter, $D$ & $\mathrm{~mm}$ & $500,660,1000$ & $500,660,1000$ \\
\hline Pipe thickness, $d$ & $\mathrm{~mm}$ & $15,25,30$ & $15,25,30$ \\
\hline $\begin{array}{l}\text { Corrosion pit } \\
\text { radius, } \Omega\end{array}$ & $\mathrm{mm}$ & $25,50,75,100$ & $10,25,50,75,100,150$ \\
\hline Pit depth, $\tau$ & $\mathrm{mm}$ & $5,10,15,20,25$ & - \\
\hline Patch inclination, $\alpha$ & degree & - & $15,30,45,60,75,90$ \\
\hline
\end{tabular}

Table 4 Coefficients defined in $S C F_{R W C}$ model

\begin{tabular}{|c|c|}
\hline Coefficient & Value \\
\hline$\alpha_{1}$ & 0.9598 \\
\hline$\alpha_{2}$ & 6.3792 \\
\hline$\alpha_{3}$ & -0.0391 \\
\hline$\alpha_{4}$ & 1.8741 \\
\hline$\alpha_{5}$ & -1.1103 \\
\hline$\alpha_{6}$ & 1.9858 \\
\hline$\alpha_{7}$ & 0.0276 \\
\hline$\alpha_{8}$ & 0.8762 \\
\hline$\alpha_{9}$ & 0.0853 \\
\hline$\alpha_{10}$ & 0.0762 \\
\hline
\end{tabular}


Table 5 Typical statistical information of physical properties in pipeline analysis

\begin{tabular}{|c|c|c|c|c|c|}
\hline \multicolumn{2}{|c|}{ Physical parameter } & \multirow{2}{*}{$\begin{array}{l}\begin{array}{l}\text { Mean } \\
\text { value }\end{array} \\
0.8 \mathrm{~m} \\
\end{array}$} & \multirow{2}{*}{$\begin{array}{l}\begin{array}{l}\mathrm{COV} \\
\text { (Others) }\end{array} \\
0.25\end{array}$} & \multirow{2}{*}{$\begin{array}{l}\text { Distribution } \\
\text { Normal } \\
\end{array}$} & \multirow{2}{*}{$\begin{array}{l}\text { Source of data } \\
\text { ACAPFP Project }\end{array}$} \\
\hline Location & Bury depth, $h$ & & & & \\
\hline \multirow{2}{*}{$\begin{array}{l}\text { Backfill } \\
\text { soil sur- } \\
\text { rounding } \\
\text { pipelines }\end{array}$} & Elastic modulus, Es & $25 \mathrm{Mpa}$ & 0.3 & LogNormal & \multirow[t]{3}{*}{ Empirical } \\
\hline & Unit weight & $20 \mathrm{kN} / \mathrm{m} 3$ & 0.1 & LogNormal & \\
\hline \multirow{4}{*}{$\begin{array}{l}\text { Pipe } \\
\text { physical } \\
\text { properties } \\
\text { (cast iron) }\end{array}$} & Elastic modulus & $100 \mathrm{Gpa}$ & N/A & Deterministic & \\
\hline & Tensile strength & $100 \mathrm{Mpa}$ & 0.1 & Normal & $\begin{array}{l}\text { Seica and Packer } \\
\text { (2004), ACA\&PFPP }\end{array}$ \\
\hline & Wall thickness & 12 to 20 & & Beta & $\begin{array}{l}\text { AIS (1941), } \\
\text { ACAPFPP }\end{array}$ \\
\hline & Pipe diameter & Varying & & Beta & \\
\hline \multirow[t]{2}{*}{ Load } & Surface load (traffic) & $50 \mathrm{kN}$ & 0.3 & Normal & ACAPFPP \\
\hline & $\begin{array}{l}\text { Operating water } \\
\text { pressure }\end{array}$ & $1000 \mathrm{kPa}$ & 0.15 & Normal & ACAPFPP \\
\hline \multirow[t]{3}{*}{ Corrosion } & Corrosion rate, $c_{\mathrm{s}}$ & $6 \mathrm{~mm}$ & 0.3 & LogNormal & \multirow[t]{3}{*}{ ACAPFPP } \\
\hline & Corrosion rate, $r_{\mathrm{s}}$ & $\begin{array}{l}0.12 \\
\mathrm{~mm} / \mathrm{y}\end{array}$ & 0.3 & LogNormal & \\
\hline & $T^{*}$ & $15 \mathrm{y}$ & 0.25 & LogNormal & \\
\hline \multirow[t]{2}{*}{ Pit size } & Top diameter, $2 \Omega_{\mathrm{U}}$ & $5 \tau \mathrm{mm}$ & 0.3 & LogNormal & \multirow{2}{*}{$\begin{array}{l}\text { Typical values } \\
\text { inferred from Hunter } \\
\text { Water pipeline } \\
\text { failure report, } \\
\text { ACAPFPP }\end{array}$} \\
\hline & $\begin{array}{l}\text { Bottom diameter, } \\
2 \Omega_{B}\end{array}$ & $4 \tau \mathrm{mm}$ & 0.3 & LogNormal & \\
\hline $\begin{array}{l}\text { Model } \\
\text { uncertainty }\end{array}$ & Model coefficient $\kappa$ & 1 & 0.15 & Normal & FEM simulation data \\
\hline
\end{tabular}

Note: Truncation applies to Normal distribution, by 3-Sigma rule.

Table 6 Weibull parameters inferred from probabilistic physical modelling when wall thickness increases with pipe diameter

\begin{tabular}{|l|c|c|c|c|}
\hline \multirow{2}{*}{$\begin{array}{l}\text { Corroded } \\
\text { pipe cohorts }\end{array}$} & \multicolumn{3}{|c|}{ Weibull parameters } & \multirow{2}{*}{$R^{2}$} \\
\cline { 2 - 4 } & $\alpha$ & $\beta$ & $T_{0}$ & \\
\hline 300 mm pipe & 3.86 & 57.55 & 0.00 & 0.998 \\
\hline $400 \mathrm{~mm}$ pipe & 5.56 & 83.44 & 0.00 & 0.997 \\
\hline $500 \mathrm{~mm}$ pipe & 6.85 & 101.80 & 6.26 & 0.998 \\
\hline $600 \mathrm{~mm}$ pipe & 4.78 & 78.83 & 53.11 & 0.999 \\
\hline
\end{tabular}

Table 7 Weibull parameters inferred from probabilistic physical modelling when wall thickness is fixed to be $15 \mathrm{~mm}$

\begin{tabular}{|l|l|l|l|l|}
\hline \multirow{2}{*}{$\begin{array}{l}\text { Corroded } \\
\text { pipe cohorts }\end{array}$} & \multicolumn{3}{|l|}{ Weibull parameters } & \multirow{2}{*}{$\begin{array}{l}\text { Fitting } \\
\text { index } R^{2}\end{array}$} \\
\cline { 2 - 4 } & $\alpha$ & $\beta$ & $T_{0}$ & 0.999 \\
\hline 300 mm pipe & 2.12 & 43.76 & 8.74 & 0.999 \\
\hline 400 mm pipe & 2.52 & 51.86 & 0.53 & 0.998 \\
\hline $600 \mathrm{~mm}$ pipe & 2.31 & 48.59 & 1.58 & 0.998 \\
\hline
\end{tabular}

